\title{
Holding a Position: \\ Public Opinion as Cognition in a Disorganized Field*
}

\author{
Andrei Boutyline \\ University of Michigan, Ann Arbor
}

October 31, 2021

(Manuscript under review)

\author{
DRAFT ONLY - \\ PLEASE DO NOT CITE WITHOUT AUTHOR'S PERMISSION
}

\footnotetext{
* I thank Neil Fligstein, John Levi Martin, Fabiana Silva, Laura Stoker, Ann Swidler, Stephen Vaisey, Robb Willer, and participants of the Berkeley Mathematical, Analytical and Experimental Sociology (MAXsoc) workshop and the Duke Culture and Cognition workshop for feedback on the paper. Direct all correspondence to Andrei Boutyline at Department of Sociology, University of Michigan, Room 3115 LSA Building, 500 S. State Street, Ann Arbor, MI 48109-1382 Email: aboutyl@umich.edu.
} 


\title{
Holding a Position:
}

\section{Public Opinion as Cognition in a Disorganized Field}

\begin{abstract}
I develop a theoretical model of the relationship between the macro-structure of political communications and the micro-structure of individuals' political attitudes. This model conceives of public opinion as a field of competition, where positions correspond to stances on issues, and are occupied both by individuals and by major political actors who compete over their support via political communications. Individuals attend to these communications to better develop their political attitudes. Since a large volume of interdisciplinary work suggests that reliably answering survey questions is an acquired cultural competency that requires substantial training to achieve, I use survey response reliability as a key measure of this enculturation. This points me to a concrete question: do patterns of survey response reliability suggest that competing ideological camps focus on the same issues? To answer this, I develop a formal latent class model of position reliability and estimate it with the 2008-2010-2012 General Social Survey panel. I find that more popular positions are generally reported more reliably than less popular ones, as would be expected if ideological camps predominantly focused on issues where they had an advantage.
\end{abstract}

Keywords: culture and cognition; public opinion; social fields 


\section{Introduction}

How reliably do people on the opposite sides of some political issue hold their positions? Our intuitions may suggest that the answer depends on the mainstream popularity of the positions in question. For example, picture someone with a position that relatively few others share, such as opposition to abortion even in cases of risk to life of mother. Both existing academic literature and popular culture frequently imagine such individuals as "true believers" (Hoffer 1951) whose positions are held all the more reliably because they place them in a clearly delineated principled minority (Hogg 2000, 2004). This line of thinking is consistent with a view that places political issues into two categories: those pitting two more-or-less mainstream popular positions against one another, where both sides hold their positions with the same reliability; and those pitting a popular position against an unpopular one, where the unpopular positions are held more reliably. I argue theoretically and demonstrate empirically that this implicit model is exactly wrong. First, equal reliability on both sides of an issue is an exception rather than the rule; and second, there is a significant and robust positive relationship between the popularity of a position and the reliability with which it is reported.

The social contours of public opinion have long been an area of interest across the social sciences. Much research has investigated two related questions: first, how individuals' demographic and cultural characteristics relate to their stances on political issues; and second, how these characteristics relate to the manner in which individuals hold and report their attitudes. So, for example, we know much about how individuals' income or religion affects their political views (e.g., Hout, Brooks, and Manza 1995; Hout and Fischer 2002); and about how their economic class, gender, age, and political knowledge influence their ability and willingness to report political attitudes (e.g., Alwin and Krosnick 1991; Delli Carpini and Keeter 1996; 
Laurison 2015; Mondak and Anderson 2004). I opened this paper by asking about principled minorities because this points to a third question, which is rarely asked explicitly: how is the relative popularity of competing issue positions within a public debate related to the way that these positions are held? While the former two questions examine how public opinion is inscribed within other sociocultural fields, this third question can lead us to understand the field of public opinion as a sociocultural entity of its own - a social structure where the dynamics of culture and cognition play out on a large scale (Foster 2018; Martin and Desmond 2010).

In this paper, I use the language of field theory to define this object of investigation (Beckert 2010; Bourdieu 1987; Fligstein and McAdam 2012; Martin 2003). In Martin's (2003) usage, social fields are abstract arenas of competition where actors hold one of a set of socially recognizable positions, and experience field effects corresponding to these positions. The public opinion fields I examine here are formed by disagreement over political issues, with field positions corresponding to different socially recognizable issue stances (e.g., "environmentalist," "pro-choice," "pro-gun"). Position occupants experience field effects in the form of motivations to think and act like those on "their side" of the field, and to repudiate the people and ideas associated with the opposing side (Iyengar and Westwood 2015; Martin 2000; Nicholson 2012).

This motivates individuals to attend to targeted streams of ideological messages from political parties, social movements, and other major political actors, who deploy these information streams to maintain, expand, or mobilize their groups of followers. Exposure to these messages structures the contents of individuals' political beliefs, and provides the cultural competencies necessary to reliably translate these beliefs into survey responses and other behaviors (Boutyline and Vaisey 2017; Carmines and Wagner 2006; Converse 1964; de Vries, Hakhverdian, and Lancee 2013; de Vries and Hobolt 2012; Zaller 1992). This exposure thus 
links individuals' field positions to their motivations and competences — a linkage that is a central property of social fields (Bourdieu 1987; Savage and Silva 2013).

As I discuss below, public opinion fields have substantially less institutionalized structure than many of the more conventional objects of field-theoretic investigation (e.g., Hoffman 1999; Wilderom and van Venrooij 2019). They may be best characterized as weak or inchoate fields, with an existence somewhere between fully formed fields and what Fligstein and McAdam call "unorganized social space" (2012:5). Nonetheless, the concept of fields is useful for analyzing public opinion both in spite and because of these divergences. Public opinion fields share enough properties with stronger fields to make field-theoretic concepts applicable. Applying these concepts to public opinion highlights how the micro-scale cultural behavior of holding reliable political attitudes is enabled by the macro-scale competition among political parties, social movements, and other political actors.

But the fields metaphor also brings out the ways that public opinion differs from more institutionalized or less contentious fields: the lack of general agreement between competitors over which political issue is the focus of their debate. Instead, as I detail below, major political actors regularly compete over the choice of issues, trying to turn the debate to issues where they are aligned with a more popular position than their opponents (Schattschneider 1975; Carmines and Stimson 1989; de Vries et al. 2013; Hacker and Pierson 2014). In Riker's (1993:3) phrasing, “[often], political disputants say with fervor: 'That's not an issue.' What they usually mean is, 'That's not an issue on which I have a winning position."' As a result, opposite positions on a political issue are generally subject to asymmetric amounts of political messaging, with popular positions receiving far more messaging than unpopular ones. 
I develop this theoretical perspective in detail below, focusing my discussion on a key consequence of this asymmetry: if individuals develop the skill for consistently reporting an issue position by attending to political messaging about it, and if political actors are more likely to focus their messaging on more popular positions, then popular positions should generally be reported more reliably than unpopular ones. To investigate this conjecture empirically, I formally develop a latent class model of position-holding within public opinion fields. I then apply it to the 2008-2010-2012 General Social Survey (GSS) panel, and find results that are consistent with my account. I conclude by outlining the implications of my results for the debate between theories that attribute the organization of political attitudes to internalized cultural schemas (Baldassarri and Goldberg 2014; Hunzaker and Valentino 2019) and those that explain it via the structure of the environment (Martin 2010; Lizardo and Strand 2010; Foster 2018).

\section{Field Structure of Public Opinion}

Below, I construct my model of public opinion fields by using the language of field theory to interweave three distinct strands of existing research: (i) the "strong effects" tradition in political communications, (ii) scholarship on the issue focus of public debate, and (iii) the "beliefsampling" perspective on survey response. The first is the long-running scholarship on the "strong effects" or "direct effects" of political communication that documents the outsize role messages from political elites play in forming popular political attitudes. The basic tenet of this theoretical tradition is the idea that individuals acquire many of their political attitudes by attending to communications from politicians, social movements, and the news media (see overviews in Bennett and Iyengar 2008; Bennett and Manheim 2006; Neuman and Guggenheim 2011). The second research strand examines which issues come to be the focus of political messaging. This scholarship observes that political actors persistently try to sway public 
attention towards issues where they are aligned with the majority position and away from those where they are in the minority (Carmines and Stimson 1989; de Vries and Hobolt 2012; Hacker and Pierson 2014; Stimson, Thiébaut, and Tiberj 2012; de Vries et al. 2013; Schattschneider 1975). My theoretical contribution below comes from (1) using the language of field theory to combine these two theoretical perspectives into a single stylized model of public opinion fields, and then (2) integrating this model with the "belief-sampling" perspective on survey response (Krosnick 1991; Tourangeau, Rips, and Rasinski 2000; Zaller 1992) to arrive at novel claims concerning the manner in which different political attitudes are held.

\subsection{The Public Opinion Field}

I use "public opinion" to mean the distribution of attitudes about politically-relevant issues within a population — or, equivalently, the distribution of a population within an abstract social space where an actor's field position corresponds to their stance on the issues defining the space (Martin 2000). Fig. 1 shows a hypothetical field formed around two issues. There are two ways to conceptualize an actor's position in such a field: in terms of her stance on any specific issue (marginal or subfield position ${ }^{1}$ ), and in terms of her stances on all the issues considered together (joint or overall field position.) Actors similarly hold identities corresponding to both specific issues and the overall field: e.g., a 'pro-life, pro-gun Conservative.'

Field institutionalization - the emergence of agreement about possible positions and the nature of the competition over them - is a key topic within sociological field theory (Jepperson 1991; Hoffman 1999; Fligstein and McAdam 2011). The public opinion subfield around an issue becomes institutionalized or settled when opposing camps reach an agreement about which issue

\footnotetext{
${ }^{1}$ To clarify, I use "subfield position" as shorthand for "an actor's position on an issue." This is not meant to suggest that the subfields operate independently from one another: rather, their degree of interdependence is an empirical question. See discussion of cross-subfield alignments below.
} 
is being debated and which stances the different sides hold on the issue. Such settlements could take the form of social norms, regulations, or internalized beliefs (Scott 1995; Hoffman 1999). For example, institutionalization of the field in Fig. 1 may mean that individuals on the left and right side of the figure functionally agree that what divides them is a disagreement on economic redistribution, where one camp wants less and the other more.

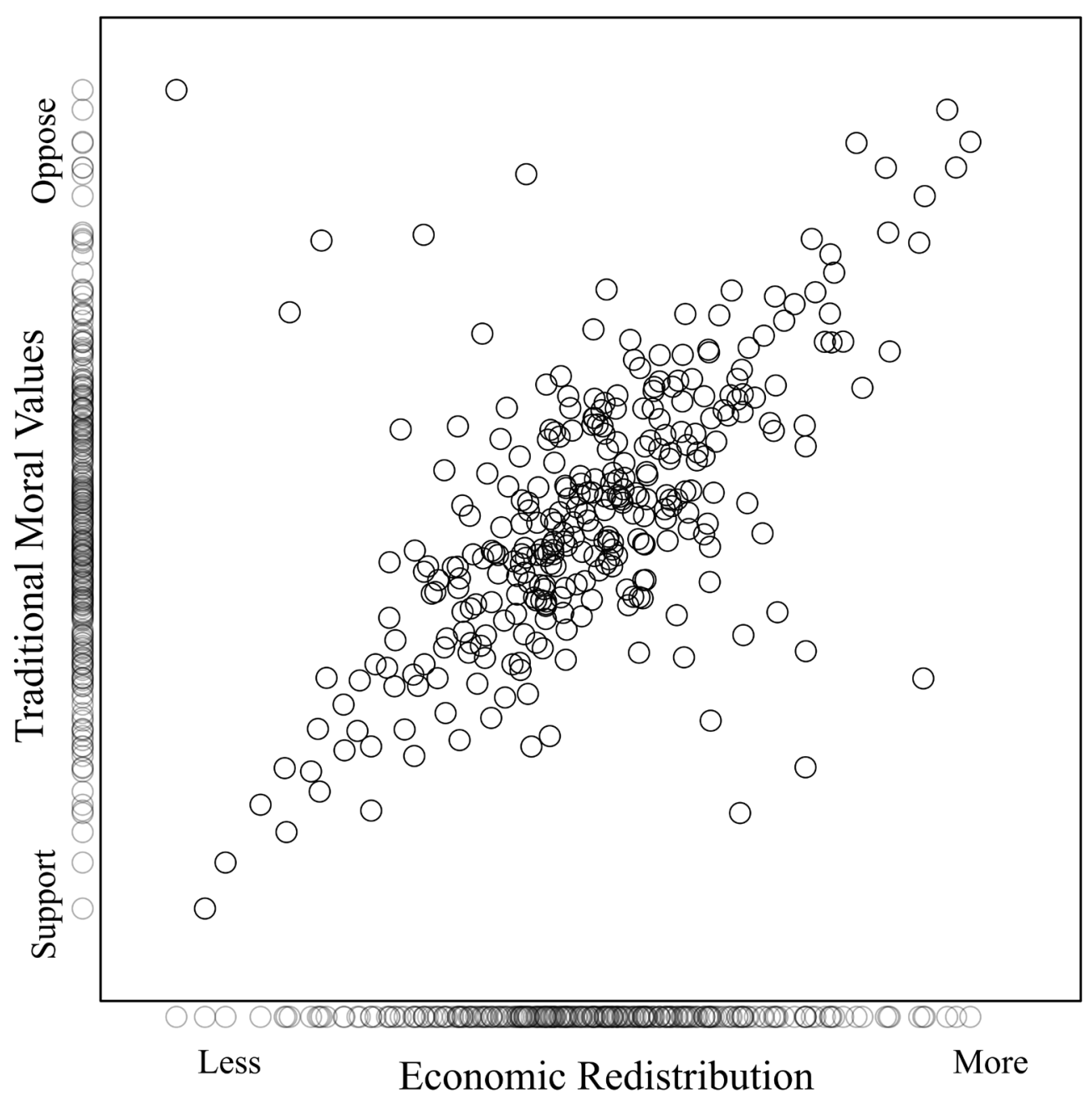

Fig. 1. Example of a Hypothetical Public Opinion Field Around Two Attitudes. Subfield (marginal) positions are below the axes. 
This "agreement on the substance of the disagreement" is a necessary component of the kinds of orderly debate envisioned by many theorists of liberal democracy (e.g., Habermas 1991; Calhoun 1992). For example, Ackerman states his "supreme pragmatic imperative" to dialog as: "if you and I disagree about the moral truth, the only way we stand half a chance of solving our problems in coexistence [...] is by talking to one another about them" (1989:10). But if the interlocutors are actually talking about different problems, it seems unlikely that their dialog, as it were, would be building towards such a solution. When opposing camps base their positions on ideological communications that feature such a disagreement about the question, they may be unprepared to engage in constructive dialog. Indeed, agreement on the disagreement behind the debate may be part of the taken-for-granted "background" speakers draw on to interpret what the other is saying (Searle 1980) rather than an actively stated part of the conversation. Casual dialog across political divisions without this basic agreement may thus create new misunderstandings rather than resolve existing ones.

In addition to the institutionalization of each subfield, public opinion fields feature a second kind of settlement: the emergence of cross-subfield alignments where two issues that previously seemed distant come to be perceived as related (e.g., as aspects of one underlying issue, or as consequences of a broader ideology.) In Fig. 1, this corresponds to the clustering of points around the diagonal. Cross-subfield alignments received considerable attention in the guise of attitude "constraint" and partisan "sorting" (e.g., Converse 1964; Boutyline and Vaisey 2017; Baldassarri and Gelman 2008; Martin and Desmond 2010; DellaPosta 2020). They were also recently the subject of an explicitly field-theoretical treatment (Martin, Slez, and Borkenhagen 2016). Here, I focus my attention primarily on the institutionalization of each subfield rather than the emergence of these alignments. In the analyses below, I instead 
encounter them as a potential source of error, which I address with robustness tests ${ }^{2}$. I return to this topic again in the discussion.

\subsection{Political Communication}

Whereas I define public opinion as a feature of how individuals are distributed across issue positions, the public opinion field also contains organizational actors who compete over these individuals' attentions and allegiances. These actors include political parties, media companies, and social movement organizations. The field model of public opinion relates features of their competition to the ways that individuals hold their opinions.

Fligstein (2001) observed that actors within social fields often attempt to influence the behavior of others by appealing to their shared identities and trying to manipulate the meanings of these identities in ways that suit their goals. Here, this strategic communication takes the form of political messaging. To mobilize supporters and expand coalitions, political parties, social movements, and other organizational actors work to frame issue positions as consistent with an ideology, and then champion them to their audiences (Carmines and Stimson 1989; Sniderman and Stiglitz 2012; de Vries and Hobolt 2012). To select information flows, individuals use their ideological or political identities — that is, their field positions - to determine which of these competing organizations are "on their side" (Broockman and Butler 2017; Cohen 2003; Sniderman and Stiglitz 2012). Individuals then attend to these "co-ideological" information streams, and use them to develop and maintain their political attitudes (for review of recent evidence, see de Vries et al. 2013). The fidelity of this information transmission from ideological producers to individuals can be thought of as the field strength at that position.

\footnotetext{
${ }^{2}$ See Appendix E.
} 
These major political actors thereby become the cultural producers behind many of the "logics" linking concrete policy stances to abstract political values and to one another, thus assembling them into seemingly coherent ideologies (Boutyline and Vaisey 2017; Converse 1964; Green, Palmquist, and Schickler 2002; Valentino 2021; de Vries et al. 2013). They also provide the public with concepts and stereotyped arguments that individuals then deploy to describe and justify their own political views (Strauss 2012), and background assumptions about how the social world operates that allow individuals to reason ideologically (Martin and Desmond 2010). In short, these ideological actors provide their audiences with the cultural skill of holding a political opinion - a skill individuals employ when reporting their attitudes during a survey interview.

\subsection{The challenge of reliability}

Scholars across different intellectual traditions have stressed that answering survey questions is an acquired cultural competency (e.g., Bourdieu 1987; Chang and Krosnick 2009; Zaller 1992). As Converse (1970:177) noted "there is a very real sense in which attitudes take practice." In this section, I review this scholarship to outline the cognitive challenge posed by survey questions, and to propose how repeated exposure to co-ideological information may help individuals overcome this challenge.

In his pioneering studies, Converse (1964) famously observed that many survey items elicit responses that are highly unreliable across panel waves and only weakly correlated to attitudes on nearby topics. His "black-and-white" model proposed that all individuals fall into one of two categories: those that hold attitudes on an issue and give perfectly consistent survey responses, and those that "offer meaningless opinions that vary randomly in direction during 
repeated trials over time" (Converse 1964:49). He thus interpreted any change in survey response as evidence that the respondent lacks a meaningful political attitude on the issue. Subsequent scholarship has rejected this strict judgement in favor of a more probabilistic view where individuals who have an opinion on a topic may nonetheless provide inconsistent responses across time due to measurement error, attitude ambivalence, or true attitude change, among other causes (Alwin and Krosnick 1991; Brody 1986; Hill 2001; Judd and Krosnick 1982; Zaller and Feldman 1992).

Nonetheless, this scholarship has also provided overwhelming evidence that survey responses often do not tap well-developed pre-existing attitudes (Tourangeau et al. 2000). Scholars have repeatedly demonstrated, for example, that substantial numbers of individuals will report attitudes about entirely fictitious entities, such as support for nonexistent bills (Schuman and Presser 1980). The amount of inconsistency that individuals exhibit in their responses across panel waves is far too high to be plausibly accounted for by true attitude change (Alwin 2007). In many cases, survey responses can also be shifted with seemingly minor experimental manipulations, such as by changing the way an issue is phrased or the order in which the questions are asked (Hill 2001; Tourangeau et al. 2000).

The established "belief-sampling" model of survey response accommodates these observations by positing that individuals select responses by first performing a stochastic search through the variously internalized cognitive contents which could potentially serve as the bases for such a choice (Krosnick 1991, 1999; Tourangeau et al. 2000; Weisberg 2009; Zaller and Feldman 1992). These “considerations" (Zaller 1992) can include prior evaluations, values, beliefs, facts, identities, vague impressions, emotional responses, and non-verbal intuitions. The 
respondent then weighs the retrieved considerations against one another to arrive at their judgement (Tourangeau et al. 2000).

Because the cognitive burden of retrieving and integrating these considerations is high, this process is guided by "satisficing", with individuals stopping their search for considerations once an apparently "good enough" set has been found (Krosnick 1991; Roberts et al. 2019). Responses on attitude questions are therefore generally based on a small, biased convenience samples of internalized considerations (Tourangeau et al. 2000). Thus, rather than accessing factual reports of well-formed pre-existing attitudes, surveys instead generally elicit "temporary constructions" (Wilson and Hodges 1992) stitched together from a shifting collection of diverse considerations. Since most individuals have at least some opposing considerations on most issues, this often results in the same individual choosing different responses at different times.

There are at least two routes by which additional exposure to co-ideological messages increases the reliability of the attitude reports arising from this process. Consider an individual whose pro-gun stance led her to join a gun owner's association, which now regularly mails her postcards. Each successive postcard could either (i) repeat pro-gun considerations already contained in the previous postcards, thus increasing their accessibility and salience (KnoblochWesterwick 2012; Roskos-Ewoldsen, Roskos-Ewoldsen, and Carpentier 2008); or it could (ii) provide new considerations in support of gun ownership. These possibilities mirror two key ways that individuals achieve response reliability under the belief-sampling model—by acquiring a highly salient set of considerations that become activated whenever the issue is raised (Fazio 1995); or by accumulating far more considerations that favor one position than the others so that different samples still generally point to the same conclusion (Tourangeau et al. 2000:182-83). 
As I argued above, individuals' field positions expose them to position-specific streams of ideological information. Individuals in different field positions thus likely come to acquire cultural competencies for answering different sets of attitude questions. This makes the reliability with which the holders of a given position report attitudes consistent with that position a key measure of field strength at a given point in the space of attitudes: positions frequently reiterated by political messaging should have higher reliability than those less frequently rehearsed. This link between field position and attitude reliability is captured by the phrase "to hold a position," which can mean both "to have an opinion" and "to stand without wavering."

\subsection{Field settlement}

Recall that the institutionalization or settlement of a public opinion field involves the emergence of a de-facto consensus between opposing camps about which issue is being debated. An idealized image of a fully settled public opinion field thus involves a public debate where opposing groups of elites focus their messaging on two contrasting answers to the same underlying question-e.g., two different solutions to the same issue or two different evaluations

of the same person. Exposure to these elite communications would then, ceteris paribus, provide individuals in the two camps with symmetrical cultural training in advocating their respective positions. Conversely, if this field settlement were absent, opposing elites would compete with each other over issue choice by focusing their communications on two different underlying questions. Individuals in one camp would then presumably be best prepared to reliably answer different questions than individuals in the other camp. Thus, symmetrical reliability between two opposing positions appears possible in a settled public opinion field but unlikely in an unsettled public opinion field. 
A substantial body of research on issue competition in political science and framing contests in sociology suggests that the field of public opinion is highly unsettled. Rather than having a set of norms confining disagreement to agreed-upon issues, competition over issues itself appears to be the norm. This field settlement may be so elusive in part because the choice of issues can have significant electoral consequences. Most political issues do not split the voting population into two even groups, and, when an issue becomes salient to voters, this provides an advantage to the political actors aligned with the majority position. Many scholars have thus observed that political actors persistently attempt to sway public debate towards topics where they have majority support (Carmines and Stimson 1989; de Vries and Hobolt 2012; Stimson et al. 2012; de Vries et al. 2013; Bawn et al. 2012; Hacker and Pierson 2014). The same avoidance of unpopular positions has been documented in the messaging strategies of ideologically extreme politicians, who focus their public messaging on popular bipartisan causes to divert attention from their unpopular policy goals (Henderson 2021).

For example, consider a hypothetical two-party system where the one party's economic policies benefit the wealthy elite while their opponents' benefit the middle class. This party may then be at a substantial disadvantage in elections fought over economic redistribution. However, because most people pay little attention to politics and are thus aware of only those party stances that receive wide and persistent coverage (Delli Carpini and Keeter 1996), the first party may be able to avoid paying an electoral penalty for its unpopular position by shifting focus to a different issue. It may thus stay quiet on economic policy and focus its messaging on issues where it holds a more popular position - for example, on racial issues, where its views may be aligned with the majority racial group. As a result, as Schattschneider (1975) noted, "political conflict is not like an intercollegiate debate in which the opponents agree in advance on a definition of the issues." 
Instead, "the antagonists can rarely agree on what the issues are because ... the choice of conflicts allocates power" (1975:66).

Even when opponents are forced to focus on the same broad issue domain, they engage in framing contests and competitions over problem definitions that aim to shift focus to advantageous sub-issues (e.g., Bloemraad, Silva, and Voss 2016; Daviter 2007). For example, in her classic study of abortion politics, Luker (1985) divided reasons for abortion into "hard" ones (e.g., risk to life of mother or pregnancy from rape), where public support for the pro-choice position was high, and "soft" ones (e.g., woman does not want or cannot afford to raise child), where it was lower. The pro-choice movement thus worked to focus the public debate on these "hard" cases, and the pro-life on "soft ones." Moreover, rather than asserting the pro-life position on the "hard" cases, the pro-life camp dismissed their relevance, arguing that modern medicine virtually eliminated situations where the mother's life is pitted against that of the child and that "something biological happens to rape victims that precludes the possibility of pregnancy" (Luker 1985:235) — a widely discredited argument that nonetheless was reiterated by pro-life Senate candidates as recently as 2010 .

Another example that displays both of these tactics — switching to a more favorable subissue within a domain, or pivoting to an entirely different domain — comes from Vedres's (2021) examination of political messaging in 1997 Hungary, where the governing party's communications marshalled positive economic indicators to argue that their policies are decreasing inflation and bringing GDP growth. The opposition first responded by focusing on a different aspect of the economy. They argued that the macro-economic indicators are not meaningful, and proposed that that "employees and small businesses are struggling despite what macro-economic indicators say" (Vedres 2021:10-11). Then, after finding that this position was 
not resonating with the public, the opposition switched its messaging to government overreach, arguing that the government's actions show that it harbors totalitarian ambitions. The two sides' messaging thus eventually focused on two entirely different issue domains.

In U.S. politics, Republicans often similarly respond to Democrats' social policy stances with claims about government overreach. For example, while Democratic senators' messaging regarding the Affordable Care Act focused on the greater access to and affordability of health care—both highly popular positions_-Republican senators most commonly responded by stoking fears of creeping government control (Hopkins 2018). All of these examples illustrate a common and well-documented political strategy: when messaging from one camp advocates a popular position on an issue, their opponents often respond by attempting to steer public attention to a different issue (Carmines and Stimson 1989; de Vries et al. 2013; Bawn et al. 2012; Hacker and Pierson 2014; Schattschneider 1975). As a result, popular positions may receive far more public advocacy than unpopular ones.

\section{Summary of Claims}

Positions in the public opinion field are occupied by individuals and by major political actors who attempt to mobilize them via ideologically targeted streams of political communications. By attending to communications from actors sharing their field positions, individuals can acquire the ability to reliably answer survey items about the political issue in question. Different field positions may thus provide their occupants with distinct sets of cultural competencies. Because public opinion fields have a low degree of institutional settlement — rather than debating an agreed-upon set of issues, actors compete over which issues should be debated—opposing positions on any given issue usually do not receive equal amounts of messaging exposure. I thus predict that: 
$H_{1}$ : Adherents of opposing positions on any given issue generally exhibit different amounts of reliability when reporting their position on the issue.

Moreover, political actors focus their communications on those positions where they have an advantage. Even when addressing the same broad issue category, they seek to focus their messaging on specific issues where their stance is more popular, and avoid communicating about those where it is less popular. I thus also predict that:

$\mathrm{H}_{2}$ : All things being equal, adherents of a more popular issue position report this position more reliably than adherents of a less popular position on the same issue.

\section{Method}

\subsection{Position-Holding Model}

To arrive at an estimator for position reliability, I begin by formalizing a "position-holding model" of survey response. The basic idea behind the model is that the public opinion subfield around any issue contains competing positions which may differ from one another in how reliably their occupants report these positions on the survey. I first assume that the set of meaningfully different response options to a given question corresponds to the set of possible positions (I relax this assumption below.) While respondents' answer choices across $t$ survey waves are observed, their true positions are unobservable. This is thus a latent class model, with latent classes representing positions ${ }^{3}$.

This model is somewhat different from more common applications of latent class analysis (LCA) in that the number and meaning of the classes is known by design rather than determined inductively. This domain-specific deductive approach has the advantage of allowing a simpler and more intuitively interpretable formal language than the one generally used for LCA (e.g.,

\footnotetext{
${ }^{3}$ For an overview of existing applications of latent class models to survey error, see Alwin (2007).
} 
Goodman 1974) ${ }^{4}$. In Appendix A, I use this approach to formalize this model of position-holding and my hypotheses about unequal reliability and the relationship between popularity and reliability. I then formally derive the model's likelihood function and show how it can be used to estimate the relevant parameters from panel data. In the remainder of the section, I provide a brief overview of this material. This overview is intended for readers who already understand the formal machinery behind latent class models, as well as general readers who may not be interested in these formal details. Mathematically-minded readers who are not already familiar with the formal workings of latent class models may instead prefer to read Appendix A before skipping forward to the "Model Specification" section.

Consider the question “do you support the death penalty?", which has two response options, "yes" $(y)$ and "no" $(n)$. I first assume that each respondent has some unobserved true position-in this case, either "Yes" $(Y)$ or "No" $(N)$. I will be interested in the popularity of the two positions, which are the probabilities $P(Y)$ and $P(N)$ of respondents holding these positions, and in the reliability with which respondents in position $Y$ answer $y$, and those in position $N$ answer $n$, which are the conditional probabilities $P(y \mid Y)$ and $P(n \mid N)$.

Since the process of question answering is stochastic, a respondent's answers do not have to correspond to their latent position, which makes it possible that someone whose true position is "no" could have answered "yes, yes, yes" on the three survey waves. To provide a link between true positions and observed responses, I assume only that the respondent whose true

\footnotetext{
${ }^{4}$ The main benefit of my domain-specific deductive approach is that it clarifies the model and the interpretation of its results. It also slightly simplifies the optimization problem faced by the approximate maximum likelihood estimator because assumption (1) limits the parameter space. However, in informal testing, I found that I was usually able to arrive at the same or similar estimates by applying LCA inductively and interpreting the estimated classes based on their conditional probabilities. In most cases, the estimates already obeyed assumption (1), and when they did, they were approximately equal to those produced by this model.
} 
attitude is Y is more likely to respond with a "yes" than with a "no," and vice versa. Formally, this "linking assumption" can be stated as:

$$
\begin{aligned}
& P(y \mid Y)>P(n \mid Y) \\
& P(n \mid N)>P(y \mid N)
\end{aligned}
$$

Or more broadly:

$$
P(x \mid X)>P(z \mid X) \forall z \neq x
$$

The null hypothesis of equal position reliability is then:

$$
H_{0}: P(y \mid \mathrm{Y})=P(n \mid \mathrm{N})
$$

Conversely, the alternate hypothesis of unequal position reliability becomes:

$$
H_{1}: P(y \mid \mathrm{Y}) \neq P(n \mid \mathrm{N})
$$

Finally, the hypothesis that more popular positions are held more reliably can be rendered (with some simplification) as:

$$
H_{2}: \operatorname{cor}[P(X), P(x \mid X)]>0
$$

In Appendix A, I continue this example to flesh out the model, and derive a likelihood function that can be used to estimate these parameters from panel data. If $T$ is a contingency table cross-tabulating responses to the death penalty question across three waves, where cells $T_{1}$ through $T_{8}$ contain the counts of respondents whose three-wave answer sequences were yyy, nyy, yny, yyn, ynn, nyn, nny, nnn, respectively, this likelihood function equals:

$$
\begin{aligned}
\mathcal{L}(T)=\left(\begin{array}{c}
\Sigma_{i} T_{i} \\
T_{1}, \ldots, T_{8}
\end{array}\right) *\left[P(y \mid \mathrm{Y})^{3} P(\mathrm{Y})+P(y \mid \mathrm{N})^{3} P(\mathrm{~N})\right]^{T_{1}} * \\
*\left(3 *\left[P(y \mid \mathrm{Y})^{2} P(n \mid \mathrm{Y}) P(\mathrm{Y})+P(y \mid \mathrm{N})^{2} P(n \mid \mathrm{N}) P(\mathrm{~N})\right]\right)^{T_{2}+T_{3}+T_{4}} * \\
*\left(3 *\left[P(y \mid \mathrm{Y}) P(n \mid \mathrm{Y})^{2} P(\mathrm{Y})+P(y \mid \mathrm{N}) P(n \mid \mathrm{N})^{2} P(\mathrm{~N})\right]\right)^{T_{5}+T_{6}+T_{7}} * \\
*\left[P(n \mid \mathrm{Y})^{3} P(\mathrm{Y})+P(n \mid \mathrm{N})^{3} P(\mathrm{~N})\right]^{T_{8} .}
\end{aligned}
$$


This model can be estimated from three-wave data via approximate maximum likelihood. In Appendix A, I generalize this likelihood function to models with any number of panel waves, response options $\mathcal{A}=\{a, b, \ldots, z\}$, and latent positions $\Omega=\{A, B, \ldots, Z\}$. I also provide details of model estimation. To enable maximum flexibility in model specification, I implemented my own estimation software in Python (see "Estimation Software" in Appendix A.)

\subsection{Model Specification}

To keep notation consistent across models, I will describe two-position, two-response option models like the one in the introductory example as:

$$
\text { Model 1. } \mathcal{A}=\{a, z\}, \Omega=\{A, Z\}
$$

Model 1 assumes that each respondent has some true position in the space of attitudes. This assumption, which is present in various forms in many methods of analyzing survey data, has been frequently criticized as untenable (e.g., Bourdieu 1972; Krosnick 1991; Martin 2000; Perrin and McFarland 2011). Some respondents may have no opinions at all on the issue they are asked about, or may not wish to exercise the effort necessary to assess their positions. Such respondents may be especially likely to change responses between waves. I thus extend my position-holding model to account for such respondents.

Prior work has identified a number of different forms of "strong satisficing" (Krosnick $1991 ; 1999)$ that allow a respondent to answer a survey item without recourse to an issue position: (i) choosing a neutral response option or the "no change" alternative; (ii) answering “don't know"; (iii) “coin-flipping”, or randomly choosing between the options offered; and (iv) "non-differentiating," or giving the same answer to all questions that have the same response 
options. Of these strategies, all except non-differentiation can be accounted for with changes to the position-holding model. ${ }^{5}$

Questions that offer a neutral or non-contentious response option can let a respondent avoid asserting an ideological position on an issue. In the GSS data I use here, the middle response category on questions with odd numbers of response options can serve this purpose (e.g., "neither agree nor disagree," "neither," "both," or the middle of a numerical thermometer.) On questions that posit two different alternatives to the status quo-e.g., whether the immigration levels should be increased or decreased — choices like "the current levels are about right" can also function as ways for respondents to seemingly avoid taking a stand (Krosnick 1991). ${ }^{6}$

These kinds of items can be modelled by including a neutral respondent class $\emptyset$ and neutral response option $v$ :

$$
\text { Model 2a. } \mathcal{A}=\{a, v, z\}, \Omega=\{A, \emptyset, Z\}
$$

While classes $\mathrm{A}$ and $\mathrm{Z}$ correspond to actual positions on a contested topic, the defining characteristic of respondents in class $\emptyset$ is their refusal to choose between the ideological choices offered. I thus do not link class $\emptyset$ to response $v$ via the linking assumption (1). I instead let the probabilities $P(a \mid \varnothing), P(v \mid \varnothing)$ and $P(z \mid \varnothing)$ vary freely. Model 2a can be estimated from 3-wave panel data ${ }^{7}$.

To opt out of taking a position by picking a neutral response, respondents must still make enough distinctions between the categories to recognize which one is neutral or non-contentious.

\footnotetext{
${ }^{5}$ I discuss "don't know" answers in Appendix H.

${ }^{6}$ Since the status quo itself may have changed between 2008 and 2012, the inclusion of these items may bias my estimates of unreliability. To ascertain that the differences in reliability I observe in this manuscript are not due to these items, I repeated my primary analyses with the relevant items omitted. I found that this did not substantively alter the results. See Appendix I for details.

${ }^{7}$ Per Appendix A, 3-wave, 3-category items have table $d f=10$, while model 2a has $d f=9$.
} 
Respondents who are even more disengaged or disinterested could go further and engage in “mental coin flipping” (Krosnick 1991:220, see also Krosnick 1999; Barge and Gehlbach 2012), i.e., pick an answer choice at random.

To account for such respondents, model 2a can be expanded with a second neutral class $\emptyset_{\mathrm{U}}$, whose members select a response option at uniform random:

$$
\begin{gathered}
\text { Model 2b: } \mathcal{A}=\{a, v, z\}, \Omega=\left\{A, \emptyset, \emptyset_{\mathrm{U}}, Z\right\} \\
P\left(a \mid \emptyset_{\mathrm{U}}\right)=\cdots=P\left(z \mid \emptyset_{\mathrm{U}}\right)=\frac{1}{|\mathcal{A}|}
\end{gathered}
$$

Alternately, in an effort to give a safer answer, respondents choosing a response at random could be proportionally more likely to pick popular responses than unpopular ones (e.g., because they are imitating the position they most recently heard voiced by someone else.)

Such a class of respondents $\emptyset_{P}$ yields the following model: ${ }^{8}$

$$
\begin{gathered}
\text { Model 2c: } \mathcal{A}=\{a, v, z\}, \Omega=\left\{A, \emptyset, \emptyset_{P}, Z\right\} \\
P\left(x \mid \emptyset_{P}\right)=P(x) \forall x \in \mathcal{A}
\end{gathered}
$$

The marginal response probability $P(x)$ can be estimated by plugging in the empirically observed frequency of $x$. I will use BIC and likelihood ratio tests to select between models $2 \mathrm{a}$, $2 \mathrm{~b}$, and $2 \mathrm{c}$.

\subsection{Regression analyses}

Applying the above models to panel data yields a new dataset with positions rather than individuals as the units of analysis. Each survey item yields two observations. For example, the item "Should abortion be legal in cases of risk to life of mother" yields one observation for the

\footnotetext{
${ }^{8}$ It is not possible to include classes $\emptyset_{\mathrm{U}}$ or $\emptyset_{P}$ with 2-category, 3-wave items because model 1 already uses all the available degrees of freedom $(d f)$. However, there are just enough $d f$ to include one for 3-category, 3-wave items: per Appendix A, their table $d f=10$, and because (3) and (4) both fix two parameters, model $2 b d f=$ model $2 c d f=|\Omega| *|\mathcal{A}|-2=10$.
} 
pro-choice position on this question (A), and one for the pro-life position (Z), and contains estimates of their popularity, $\mathrm{P}(\mathrm{A})$ and $\mathrm{P}(\mathrm{Z})$, and their reliability, $\mathrm{P}(\mathrm{a} \mid \mathrm{A})$ and $\mathrm{P}(\mathrm{z} \mid \mathrm{Z})$. To test my hypotheses, I first contrast the reliability of opposing positions visually and via bivariate analyses. I then examine the relationship between the reliability of each position and its popularity with multiple regression. Because reliability estimates for two-category and threecategory items cannot be directly compared ${ }^{9}$, I examine the two item sets separately.

There are three kinds of confounds these regression analyses need to rule out: differences between respondents, differences between survey items, and population-level attitude trends. An extensive literature documents the effects of question and respondent characteristics on response reliability. Since my hypotheses concern only the characteristics of positions, these effects would present themselves as confounds to be eliminated. First, some questions place fewer cognitive demands on the respondent, and are thus easier to answer reliably than others. Question characteristics including topic, clarity of phrasing, number of response categories, and place in the survey may affect reliability (e.g., Holbrook, Cho, and Johnson 2006; Alwin 2007). Because each question in the survey corresponds to two different positions in these analyses, I can use question-level fixed effects to eliminate such question-level confounds.

Second, individuals occupying different issue positions may vary in ways that affect their response reliability. For example, respondents who are higher educated, more politically involved, more motivated, or have better memory or verbal ability can be expected to provide more reliable responses to the survey questions than those who are not (Alwin and Krosnick 1991; Kaminska, McCutcheon, and Billiet 2010; Schuman and Presser 1996). It is thus necessary

\footnotetext{
${ }^{9}$ By (1) and law of total probability, reliability $P(x \mid X)$ has range $1 /|\mathcal{A}|<P(x \mid X) \leq 1$, where $|\mathcal{A}|$ is the number of response categories.
} 
to rule out the possibility that differences in the reliability of positions stem from differences in the characteristics of respondents that occupy them.

One approach to ruling out this confound would involve estimating position-level controls for the average demographic characteristics of position occupants. Note, however, that demographic characteristics are theorized to influence a respondent's general ability to reliably answer survey questions, and it is this ability which affects the respondent's reliability on a particular position. Thus, rather than controlling for demographic characteristics, a more direct solution is to control for respondents' general ability to answer question reliably. ${ }^{10}$ Each respondent in the data answered at least 66 three-wave items. To create this control variable, I use Bayes rule to estimate each respondent's reliability on all other two- or three-category items, and use these estimates to create individual-level indexes of each respondent's reliability. I then again apply Bayes rule to transform these estimates into position-level controls for expected occupant reliability (see Appendix C.)

The third potential confound can come from broad shifts in public opinion. For example, the first decade of the $21^{\text {st }}$ century saw a general liberalization of attitudes regarding gay rights. As a result, many respondents who reported anti-gay marriage views in wave 1 could be expected to change their responses in later waves. Since the position-holding model does not itself take time trends into account, it cannot distinguish position instability that is due to unreliable reporting from position instability due to attitude change. I thus include a control for shifts in the marginal popularity of a position between panel waves.

\footnotetext{
10 The structure of these data make it impossible to use individual-level fixed effects; this approach, however, approximates the logic of fixed effects by focusing on the variance in reliability around an individual's mean.
} 


\section{Data}

I tested my hypotheses with data from the 2008-2010-2012 GSS Panel $(\mathrm{N}=1294)^{11}$. I examined all questions that (a) concerned a subjective attitude on a political issue, broadly construed, and (b) were asked on all three panel waves. There were 107 such questions, covering abortion attitudes (7 questions), government spending (28), confidence in major institutions such as the press or the Supreme Court (12), crime and punishment (4), freedom of unpopular speech (15), gender and marriage (9), race/racism (8), police violence (5), sexuality (5), limits of government (5), right to suicide (5), school prayer(1), immigration (1), and a future world war (1). ${ }^{12}$ See Appendix Table D1 for item details, and Appendix H for further coding decisions.

While two- and three-category items always featured a clear qualitative distinction between categories (e.g., "agree" vs. "neither agree nor disagree," or "agree" vs. "disagree”), items with four or more categories had some categories that differed only in intensity. Categories that differ only in intensity rarely correspond to identifiably different positions within the public debate. For example, the four-category item probing agreement with "teens should have access to birth control even if their parents do not approve" ("strongly agree," "agree," "disagree," and "strongly disagree") corresponds to two clearly distinct ideological camps rather than to four. A respondent who shifts between "agree" and "disagree" across panel waves thus exhibits a different sort of unreliability than a repondent that adds or removes the modifier "strongly" from her answer. To avoid conflating shifts across field positions with shifts in intensity, I recoded all items to treat categories that differed only in intensity as equivalent, thus collapsing items with four or more categories to two categories if the number of categories was even (52 items), and

\footnotetext{
${ }^{11}$ Available at http://gss.norc.org/Documents/stata/GSS_2008_Panel_Stata.zip

${ }^{12}$ I excluded one question because its highly skewed response distribution caused problems with estimation: $92.4 \%$ of non-missing responses endorsed sex education in public schools.
} 
three if odd (55 items). Below, I use separate sets of regressions to analyze the resulting twocategory items and three-category items. Appendix Table D1 contains mnemonics for positions on the opposite ends of ends of each resulting item, which I labelled "A" and " $Z$ " (to reiterate, the choice of which response is labelled $\mathrm{A}$ or $\mathrm{Z}$ is arbitrary; labels only indicate that positions are on opposite ends ${ }^{13}$ of an issue).

\section{Results}

\subsection{Position-Holding Model Estimates}

\subsubsection{Two-category items}

I began by applying model 1 to the 52 two-category items. Results are plotted in Fig. 2, where each item's coordinates correspond to the estimated reliability of the first (A) and last (Z) issue positions. For example, the item asking whether it is acceptable for police to strike a murder suspect has coordinates $(0.57,0.95)$, indicating that the reliability of the "yes" and "no" positions are $\mathrm{P}(\mathrm{a} \mid \mathrm{A})=0.57$ and $P(z \mid Z)=0.95$. These estimates are detailed in Appendix Table D1. Across all 104 positions, the average reliability is 0.84 .

\footnotetext{
${ }^{13}$ All items were either binary or ordinal.
} 


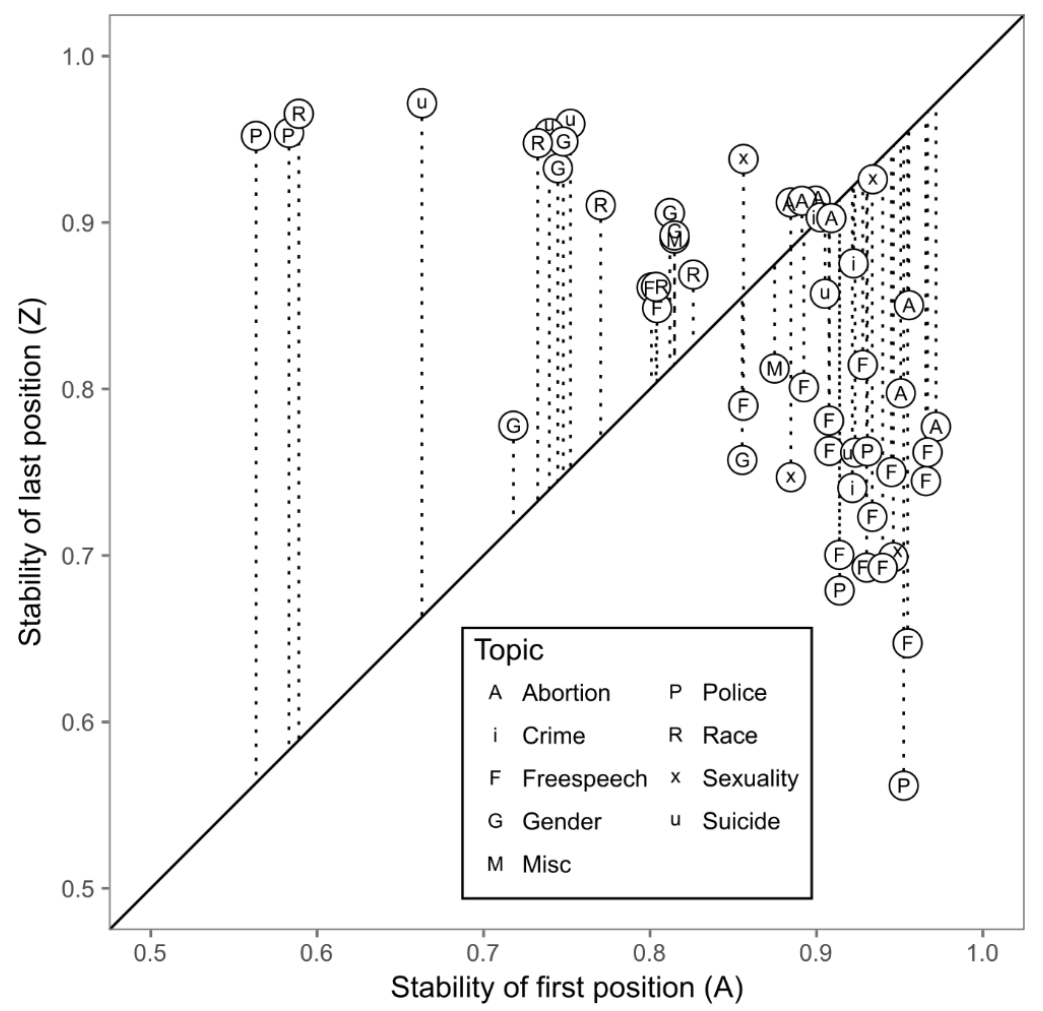

Fig. 2. Relative Reliability of Positions at Opposite Sides of 52 Two-Position Items (GSS Data). Points represent issues. Their $(X, Y)$ coordinates are the reliability of opposing issue positions, $(P(a \mid A), P(z \mid Z))$. Length of dotted lines corresponds to difference in position reliability, $|\mathrm{P}(\mathrm{a} \mid \mathrm{A})-\mathrm{P}(\mathrm{z} \mid \mathrm{Z})|$.

I now turn to differences in reliability between opposite positions. In Fig. 2, dotted lines connect each point $(\mathrm{P}(\mathrm{a} \mid \mathrm{A}), \mathrm{P}(\mathrm{z} \mid \mathrm{Z}))$ to the point $(\mathrm{P}(\mathrm{a} \mid \mathrm{A}), \mathrm{P}(\mathrm{a} \mid \mathrm{A}))$ on the diagonal. Their length thus equals $|\mathrm{P}(\mathrm{z} \mid \mathrm{Z})-\mathrm{P}(\mathrm{a} \mid \mathrm{A})|$, which is the difference in reliability between the two opposing issue positions A and Z. Across all the items, the average length of the difference $|\mathrm{P}(\mathrm{z} \mid \mathrm{Z})-\mathrm{P}(\mathrm{a} \mid \mathrm{A})|=0.15$, or $18 \%$ of the average position's reliability — a substantively large difference. It is also significantly different from $0(t=10.4, d f=51, p<0.001)$. This is consistent with Hypothesis 1, which states that the two sides of an issue do not generally have the same reliability. 


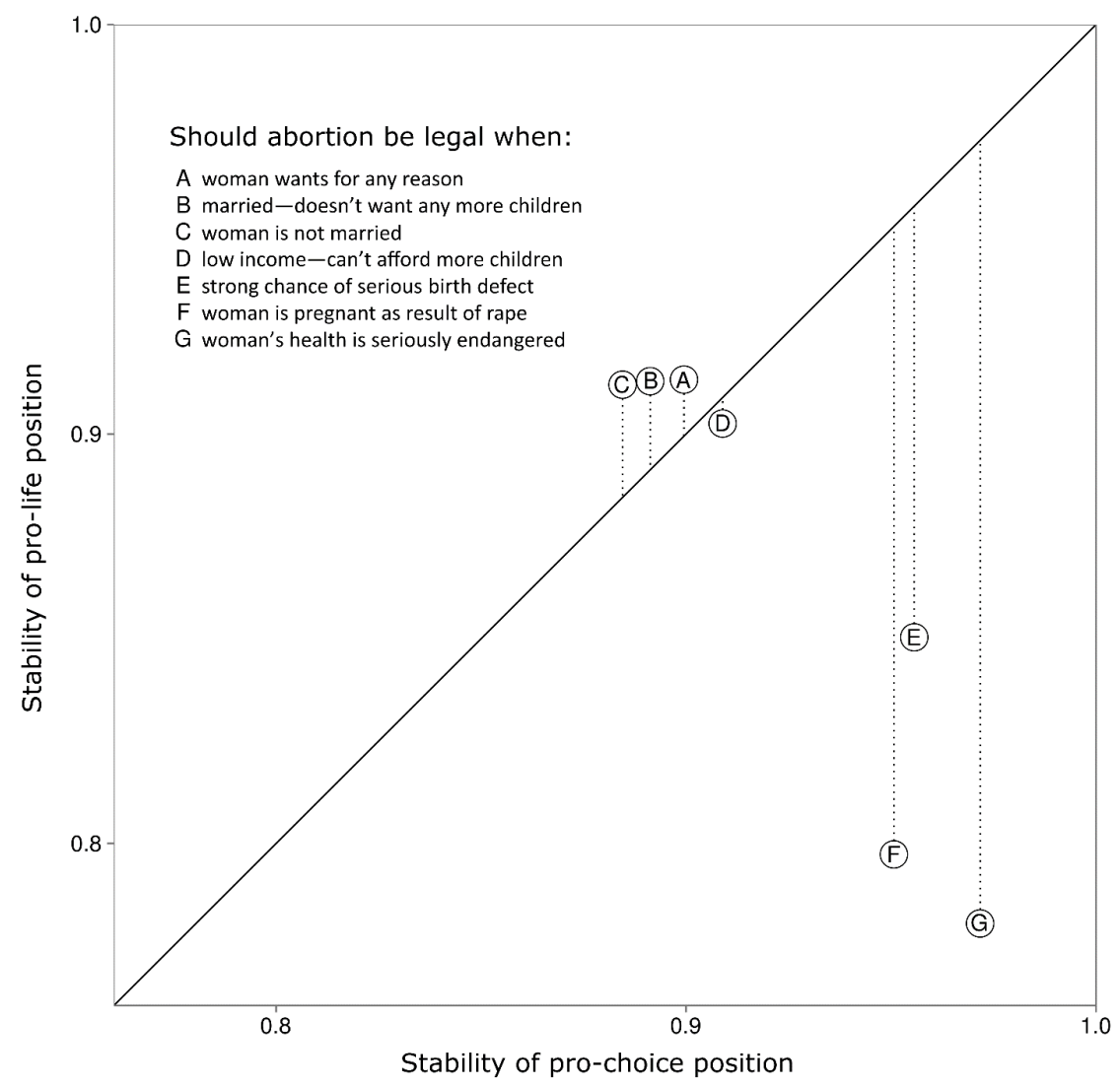

Fig. 3. Relative Reliability of Abortion Attitudes (GSS Data). See Fig. 2 caption for details.

In Fig. 3, I examine the relative reliabilities for the seven abortion items more closely. These items correspond to the different abortion cases addressed by Luker (1985). The first four items are the "soft" abortion cases: elective abortion, abortion for unmarried women, and abortion for women who do not want or cannot afford to have any more children (A-D). The remaining three are the "hard" cases of abortion when there is risk to life of mother, rape, or chance of birth defect (E-G). As I noted above, Luker argued that pro-choice activists wanted the debate to focus on the hard cases, where the pro-choice position had overwhelming public support, while pro-life activists refused to engage these questions for similar reasons. The reliability results are consistent with this asymmetry: while the pro-choice position on hard cases is exceptionally reliable, the pro-life position is relatively unreliable. 


\subsubsection{Three-category items}

To rule out the possibility that these results are due to positionless respondents, I turn to estimates produced by models $2 \mathrm{a}, 2 \mathrm{~b}$, and $2 \mathrm{c}$ from the 55 three-category items. Model $2 \mathrm{a}$ adds a class of positionless respondents that are drawn to the neutral or status-quo response category. Model $2 \mathrm{~b}$ extends $2 \mathrm{a}$ by adding a second class of positionless respondents, who act as "mental coin-flippers." Model 2c instead extends 2a with a class of positionless respondents that are proportionally more likely to pick popular responses over unpopular ones.

Since models $2 \mathrm{~b}$ and $2 \mathrm{c}$ are nested within model $2 \mathrm{a}$, they can be compared to it with likelihood ratio tests $\left(\chi^{2} d f=1\right)$. Across the 55 three-category items, likelihood ratio tests for model $2 \mathrm{~b}$ produced an average $\mathrm{p}$-value of $p=0.79$, with the lowest $\mathrm{p}$-value equaling $p=0.196$. Tests for model $2 \mathrm{c}$ produced an average $\mathrm{p}$-value of $p=0.77$, with the lowest equaling $p=0.152$. This indicates that adding a class of randomly-answering respondents to the model never brought any substantial improvements to model fit. Accordingly, model 2b's and 2c's $B I C$ scores were always greater than $2 \mathrm{a}$ 's, indicating that model $2 \mathrm{a}$ is uniformly preferable. I therefore base my further analyses on model $2 \mathrm{a}$.

The reliability estimates for positions $\mathrm{A}$ and $\mathrm{Z}$ produced by model $2 \mathrm{a}$ are plotted in Fig. 4. Across these 110 positions, the average reliability equaled 0.74 . As in Fig. 3 , the dotted lines correspond to the absolute differences between the reliability of the opposite positions on each of these questions, $|\mathrm{P}(\mathrm{a} \mid \mathrm{A})-\mathrm{P}(\mathrm{z} \mid \mathrm{Z})|$. The mean value of this difference equals 0.162 , which is $22 \%$ of the average position reliability. This difference is substantively and statistically different from $0(t=11.6, d f=54, p<0.001)$. This again offers support for Hypothesis 1 . 


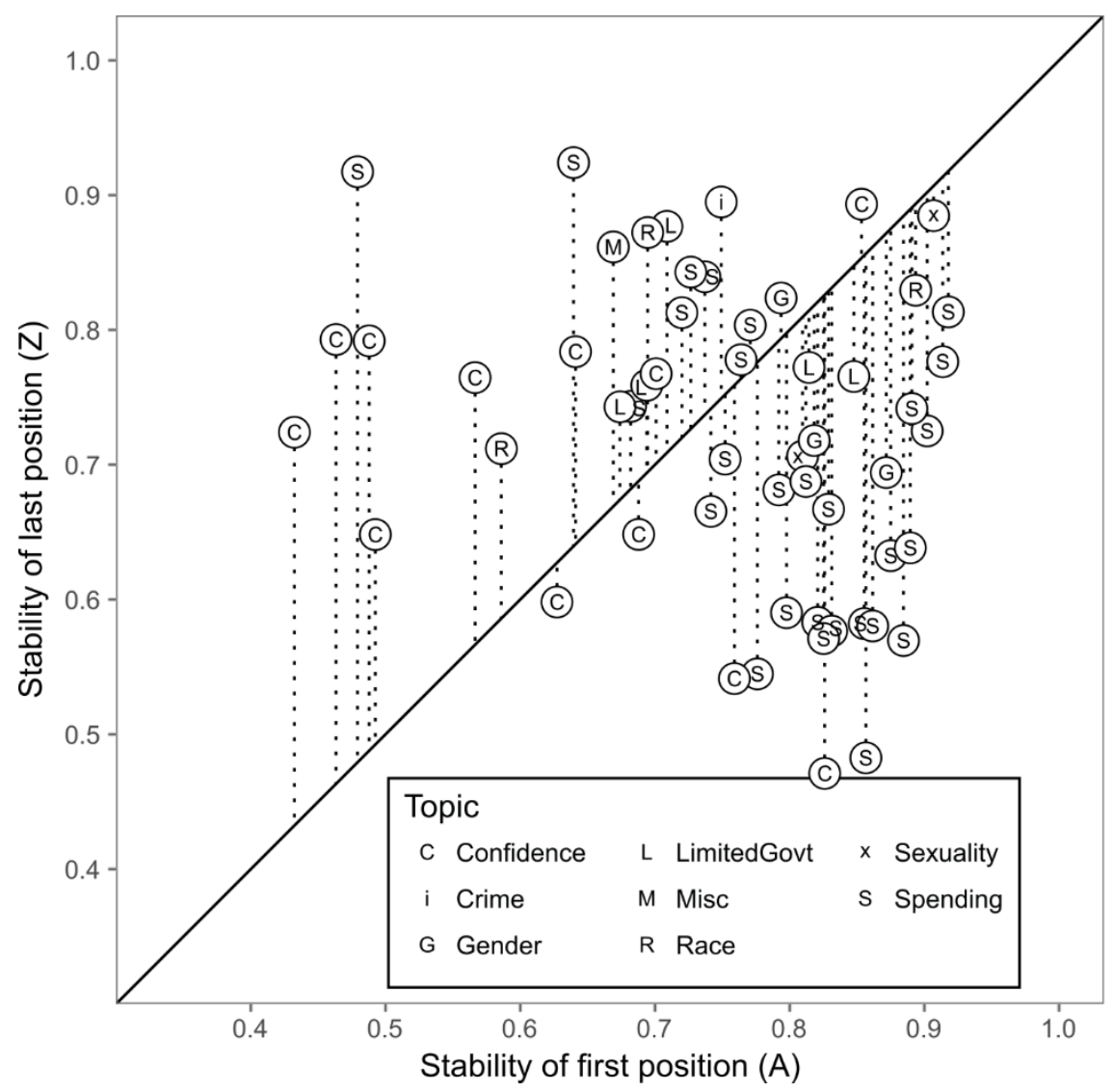

Fig. 4. Relative Reliability of Positions at Opposite Sides of 55 Three-Position Items (GSS Data). See Fig. 2 caption for details.

\subsection{Regression analyses}

I use regression analyses with results from position-holding models 1 and 2 a to test my second hypothesis, which states that occupants of more popular positions hold them more reliably than occupants of less popular ones. Because the reliability estimates from models 1 (two-category items) and 2a (three-category items) are on different scales, I again analyze them separately. To avoid confusion with position-holding models (1, 2a, 2b, and 2c), I indicate regression models with capital letters (A, B, and C).

\subsubsection{Two-category items}

I first use regression to analyze estimates produced by position-holding model 1 (Fig. 5.) The univariate regression of position reliability on position popularity is reported as Model A in 
Table 1. The regression coefficient for popularity is 0.357 ( $\mathrm{SE}=0.022, \mathrm{p}<0.001)$. Thus, when the popularity of a position increases by one percentage point, the probability that its occupants correctly report their position increases by $1 / 3^{\text {rd }}$ of a percentage point. This relationship is both statistically and substantively significant, and thus provides support for Hypothesis 2.

\begin{tabular}{|c|c|c|c|}
\hline & Model A & Model B & Model C \\
\hline \multirow[t]{2}{*}{ Popularity } & $0.357^{* * *}$ & $0.270^{* * *}$ & $0.215^{* * *}$ \\
\hline & $(0.022)$ & $(0.031)$ & $(0.040)$ \\
\hline \multirow[t]{2}{*}{ Occupant reliability ${ }^{\dagger}$} & & $0.017^{* *}$ & $0.016^{* *}$ \\
\hline & & $(0.006)$ & $(0.005)$ \\
\hline \multirow[t]{2}{*}{ Popularity change ${ }^{\dagger}$} & & $-0.018^{*}$ & $-0.038^{* *}$ \\
\hline & & $(0.007)$ & $(0.012)$ \\
\hline \multirow[t]{2}{*}{ (Intercept) } & $0.664^{* * *}$ & $0.708^{* * *}$ & $0.803^{* * *}$ \\
\hline & $(0.012)$ & $(0.016)$ & $(0.039)$ \\
\hline \multirow{2}{*}{$\begin{array}{l}\text { Item fixed effects? } \\
\qquad \mathrm{R}^{2}\end{array}$} & - & - & Yes \\
\hline & 0.715 & 0.752 & 0.911 \\
\hline Adjusted $\mathrm{R}^{2}$ & 0.712 & 0.745 & 0.813 \\
\hline $\mathrm{N}^{*}$ & 104 & 104 & 104 \\
\hline
\end{tabular}

Table 1. OLS models predicting the reliability of first and last positions for two-category GSS items. Popularity and reliability estimates are from position-holding model 1. Standard errors in parentheses.

† Standardized to $\sigma=1$.

$\$ N$ is the total number of first (A) and last (Z) item positions.

${ }^{*} \mathrm{p}<.05 ;{ }^{* *} \mathrm{p}<.01 ;{ }^{* * *} \mathrm{p}<.001$ 


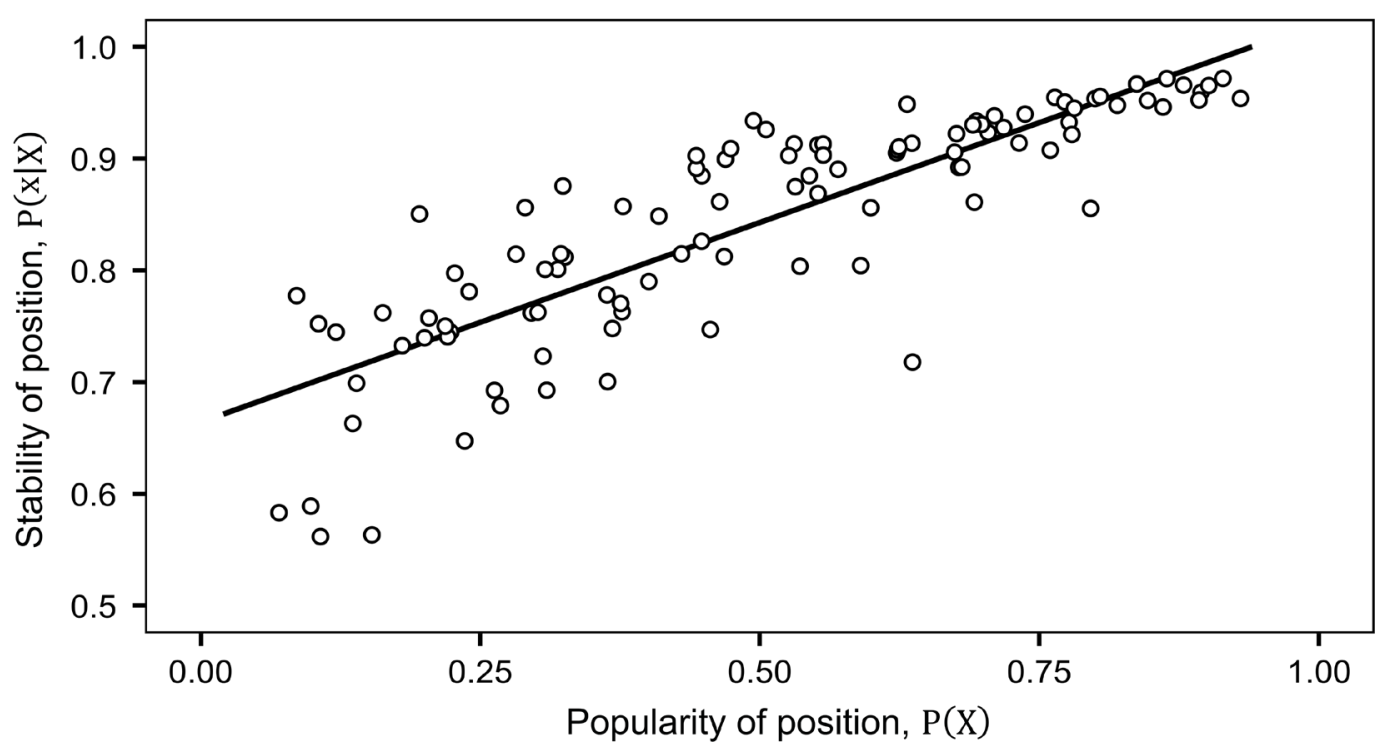

Fig. 5. Relationship between the Popularity and Reliability of Positions from 52 Two-Category Items with Lines of Best Fit (GSS Data).

In Model B of Table 1, I add controls for general reliability of occupants and change in position popularity. The coefficient for occupant reliability equals 0.017 ( $S E=0.006, p<$ 0.001), indicating that, when the occupants of a position were one standard deviation more reliable in their stances on the other 2-category items, the average reliability of that position increased by roughly 0.02 of a point. The coefficient for popularity change equals 0.018 (SE = 0.007, $p<0.05)$, indicating that, when a position experienced one standard deviation more change in popularity, its reliability decreased by roughly 0.02 of a point. Both effects are thus significant and in the predicted direction, although neither is substantively large. With these controls included, the key coefficient for the popularity of a position decreased to $0.270(S E=$ 0.031, $p<0.001$ ), but remained substantively large and highly significant statistically.

Finally, survey items differ from one another in how easy they are to answer reliably. To compensate, model $\mathrm{C}$ adds item-level fixed effects. The coefficient for popularity again decreases in magnitude but remains highly significant, equaling $0.215(\mathrm{SE}=0.040, \mathrm{p}<0.001)$. 
Thus, within each survey item, a one-point increase in position popularity is associated with a 0.22-point increase in reliability. This again provides support for Hypothesis 2.

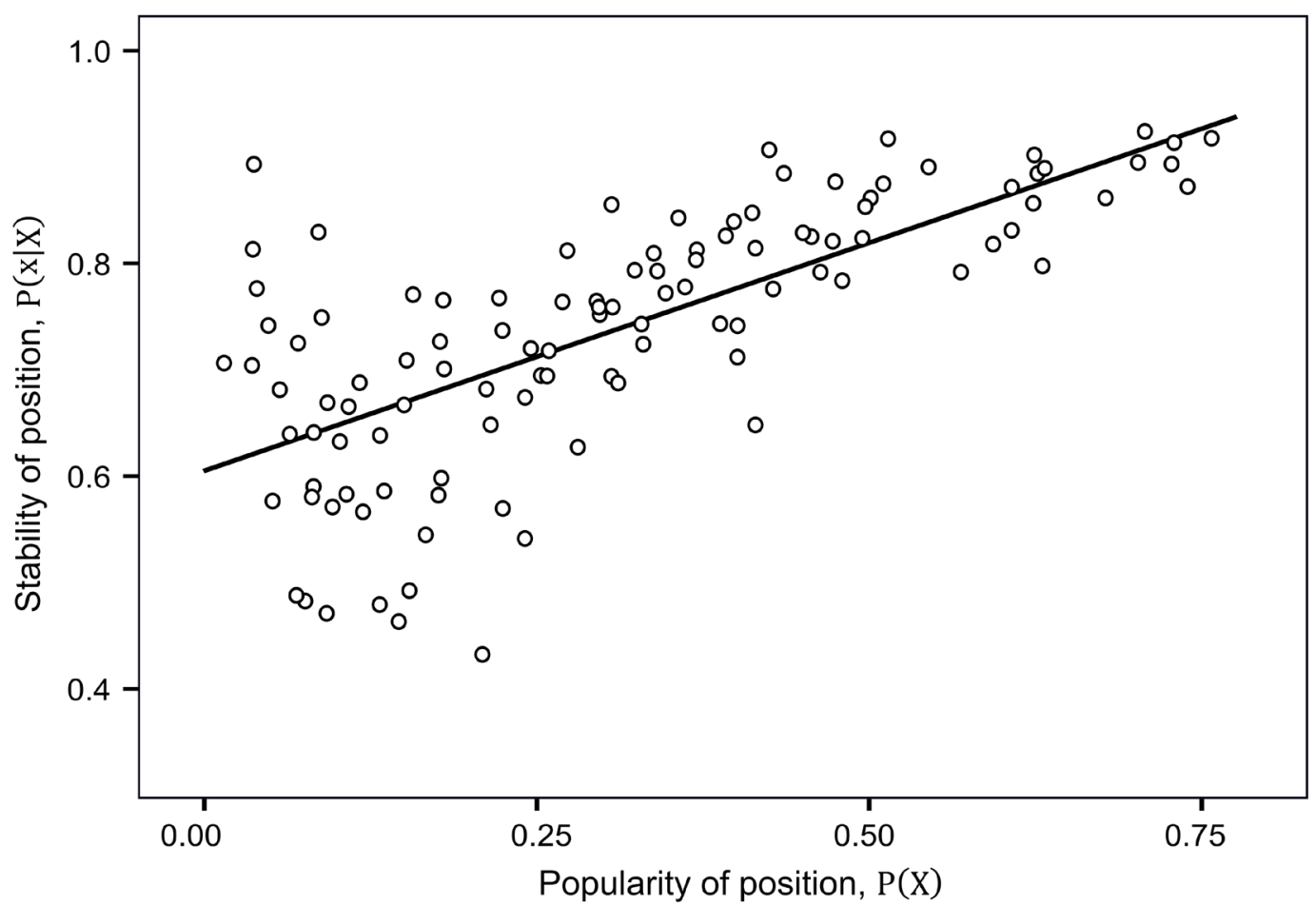

Fig. 6. Relationship between the Popularity and Reliability of Positions from 55 Three-Category Items, with Lines of Best Fit (GSS Data).

\subsubsection{Three-category items}

I now turn to regression analyses of estimates from position-holding model 2a, which accounts for positionless respondents (Table 2 and Fig. 6.) As before, Model A is the univariate regression of position reliability on position popularity. The coefficient for popularity equals 0.429 ( $\mathrm{SE}=0.041, \mathrm{p}$ $<0.001$ ), indicating that a one-point increase in the popularity of a position is associated with a significant 0.43 -point increase in reliability. 


\begin{tabular}{|c|c|c|c|}
\hline & Model A & Model B & Model C \\
\hline \multirow[t]{2}{*}{ Popularity } & $0.429^{* * *}$ & $0.378^{* * *}$ & $0.386^{* * *}$ \\
\hline & $(0.041)$ & $(0.037)$ & $(0.040)$ \\
\hline \multirow[t]{2}{*}{ Occupant reliability ${ }^{\dagger}$} & & $0.041^{* * *}$ & $0.044^{* * *}$ \\
\hline & & $(0.007)$ & $(0.008)$ \\
\hline \multirow[t]{2}{*}{ Popularity change $^{\dagger}$} & & $-0.028^{* * *}$ & $-0.024^{*}$ \\
\hline & & $(0.007)$ & $(0.011)$ \\
\hline \multirow[t]{2}{*}{ (Intercept) } & $0.605^{* * *}$ & $0.621^{* * *}$ & $0.743^{* * *}$ \\
\hline & $(0.015)$ & $(0.013)$ & $(0.047)$ \\
\hline \multirow[t]{2}{*}{ Item fixed effects? } & - & - & Yes \\
\hline & 0.505 & 0.656 & 0.864 \\
\hline Adjusted $\mathrm{R}^{2}$ & 0.500 & 0.647 & 0.714 \\
\hline $\mathrm{N}^{*}$ & 110 & 110 & 110 \\
\hline
\end{tabular}

Table 2. OLS models predicting the reliability of first and last positions for three-category GSS items. Popularity and reliability estimates are from position-holding model 2a. Standard errors in parentheses.

$\dagger$ Standardized to $\sigma=1$.

$¥ N$ is the total number of first (A) and last (Z) item positions.

${ }^{*} \mathrm{p}<.05 ;{ }^{* *} \mathrm{p}<.01 ;{ }^{* * *} \mathrm{p}<.001$

Model B adds controls for the reliability of a position's occupants on all other threecategory items and population-level popularity change of a position. The key coefficient for position popularity remains substantively large and statistically significant $(\beta=0.378, S E=$ 0.037, $p<0.001)$. Finally, in Model C, which adds item-level fixed effects, the coefficient again retains its magnitude and significance $(\beta=0.386, S E=0.40, p<0.001)$. Thus, when my analysis accounts for positionless respondents, position-level differences in occupant reliability, trends in position popularity, and item-level fixed effects, I find that a one-point increase in position popularity is associated with a 0.39 -point increase in position reliability. This again offers support for my second hypothesis. 


\subsection{Robustness checks}

Positions on different issues may be non-independent from one another (e.g., due to crosssubfield alignments). To investigate whether my results are robust to the presence of such dependencies, I performed robustness tests where I decreased the weight of non-independent positions and the power of the significance tests. These tests showed that my substantive results are robust to such non-independence (see Appendix E). I also performed simulations to ascertain that the observed relationship between popularity and reliability is not due to estimator bias (see Appendix F.) I then used another set of simulations to ascertain that my results are not an artifact of regression to the mean or biased binarization cutpoints (see Appendix G).

\section{Concluding Discussion}

In this paper, I developed "public opinion fields" as an organizing model for tying together different strands of research regarding political attitudes. I noted that existing literature suggests that public opinion fields may have a very low degree of institutional settlement: rather than having an agreed-upon set of issues to debate, actors compete over which issues should be debated. I thus predicted that the reliability of positions on opposite ends of one issue should generally not be equal. Moreover, since prior work suggests political actors focus their communications on issues where their positions are in the majority, I also predicted that the reliability of a position should be positively related to its popularity.

To test these suppositions, I developed a formal latent class model of position-holding, and estimated it with data from the 2008-2010-2012 GSS panel. The results offered consistent support for both hypotheses. Opposite positions on an issue are generally occupied with different amounts of reliability. Moreover, popular positions are generally held more reliably, as would be expected if they were the focus of much political communication; unpopular positions are held 
with more uncertainty, as would happen if they were relatively underemphasized. This fits with an image of public debate where opposing camps do not have a de-facto agreement on which issues they are debating, with each camp focusing on issues where its positions are more popular. It may be the case then that public opinion fields are not as good at sustaining substantive debate between ideologically opposed individuals as they are at creating the illusion that such a debate exists - a competition that is less like combatants jousting, and more like them tilting at different windmills.

\subsection{Future research}

\subsubsection{Statistical identification}

My position-holding model let me to estimate the popularity and reliability of positions from attitude questions asked on three or more panel waves. Applying it to the 2008-2012 GSS panel enabled me to demonstrate that the association between position popularity and reliability is strong and robust across a broad range of issues, and to show that this relationship is unlikely to arise from positionless respondents, differences in item difficulty, general shifts in position popularity, or across-position differences in respondent survey-answering skill. However, the design of this study did not enable me to isolate this relationship. To take steps towards this statistical identification, future work could begin by producing longitudinal estimates of the shifting reliability of a given position. This would allow statistical analyses to add position-level fixed effects, and thus rule out possible confounds form time-invariant aspects of each position.

The position-holding model uses all three panel waves to estimate each position's reliability. Since this model already uses all the degrees of freedom available in the data, this approach cannot be used to estimate the change in position reliability from a three-wave panel dataset. Estimating this change requires either a dataset with more panel waves, or comparisons 
across two different 3-wave panel datasets-e.g., the 2006-2008-2010 and 2010-2012-2014 GSS panels. If my theory of public opinion fields is correct, then issue positions that became more popular in the newer panel should have also become more reliable, and vice versa.

The theoretical perspective I developed here proposes that political elites target their communications at popular positions, thus increasing the reliability with which these positions are held. However, the design of the present study did not let me test whether elite communications volume indeed mediates the relationship between popularity and reliability. To study this mechanism, future research would need to supplement survey data with analyses of the issue focus of elite political communications. The volume of elite communications on an issue could be measured, for example, by analyzing press releases from members of Congress - an approach validated by Hopkins (2018). It could also be done by applying topic models to partisan news media (DiMaggio, Nag, and Blei 2013; Bonilla and Grimmer 2013). Combining these measures with longitudinal estimates of position reliability would allow the researcher to examine whether position-holding ability indeed increases when communications around the position grow in volume.

\subsubsection{Effects of political polarization}

The recent growth of political polarization in the United States may provide further opportunities to test the position-holding model's predictions. Polarization is most apparent among party elites and the members of both parties in Congress, who are now further apart than at any point since the Civil War (Hare and Poole 2014). As a result of growing party differences, the numbers of swing and splitticket voters have also dropped (Pierson and Schickler 2020; Smidt 2017; Wilson, Parker, and Feinberg 2020). These trends could decrease the political penalty for messaging that focuses on unpopular positions, thus potentially increasing its volume and weakening the key link between the 
popularity and stability of positions in the public opinion field. The growth in partisan news media may similarly increase the availability of messages promoting unpopular positions. I review empirical studies addressing both of these potential changes below.

Elites' willingness to address unpopular positions appears to differ across mediums. Recent analyses of television advertising in Congressional races show that even highly partisan candidates go to great lengths to detract attention from their partisan records by portraying themselves in advertisements as moderates or independents and stressing popular bipartisan positions (Fowler et al. 2021; Henderson 2021; Neiheisel and Niebler 2013). However, polarization is more apparent online, where politicians can target their ads at audiences composed largely of their followers. A comprehensive analysis of Facebook political advertisements from 2018 found that candidates often explicitly portrayed themselves as partisans in ads targeted at their base (Fowler et al. 2021). Twitter messages by members of Congress also exhibit open partisanship, but their contents appear markedly more partisan for Republicans, with Democrats still moderating their messages to reach a broader middle (Hemphill and Shapiro 2019; Russell 2021) — an asymmetry that parallels a substantial body of scholarship showing that Republicans are more polarized than Democrats (Pierson and Schickler 2020). And importantly, politicians' partisan Facebook ads and Twitter messages largely focus on party loyalty and contain relatively little discussion of issue positions (Bode et al. 2016; Fowler et al. 2021; Jungherr 2016). Thus, while elite endorsements of unpopular positions may now be more common than in the past, they still appear relatively rare.

Another relevant aspect of polarization is the growth of partisan news media. The past decades saw the rise of Fox News and MSNBC — two major partisan cable news channels — and a myriad of increasingly extreme niche online news outlets. These changes signal "a new, more partisan era in American journalism" (Groeling 2013:148) where the supply of highly partisan news may be higher than ever before (Van Aelst et al. 2017). However, in contrast to these dramatic changes to news supply, empirical analyses of news consumption show only modest changes (see 
overview in Van Aelst et al. 2017). The most detailed picture comes from two recent analyses of large-N representative datasets of Americans' online behaviors. First, echoing prior scholarship on news diets (Nelson 2020; Nelson and Webster 2017), Yang et al. (2020) found that the vast majority of online news consumers got news from large politically moderate outlets with ideologically diverse audiences. Second, using machine classification of millions of web pages to estimate the lean of individuals' news diets from browsing data, Guess (2021) found that the bulk of Democrats, Republicans and independents alike consumed moderate news diets that overlapped far more than they differ. However, there are also clear indications that a small portion of Americans have news diets composed largely of partisan news media, and they appear to overwhelmingly be conservative Republicans (Guess 2021; Yang et al. 2020).

In sum, despite the increasing polarization in Congress and the news media, the changes to the issue focus of elite political messages and the media diets of most Americans do not yet appear dramatic enough to fundamentally disrupt the field dynamics of public opinion. Still, the relatively modest changes that have already taken place may have pronounced effects on position holding, as some segments of the population - especially Republican users of social media — may now be exposed to unprecedented amounts of political messages advocating unpopular issue positions. This suggests two predictions that future work can test by fielding a new panel survey. First, extremely conservative positions in the newer data should be held more reliably than they were in the data I analyzed here. And second, extremely conservative positions in the newer data should be held more reliably than comparable extremely liberal positions in the same data.

\subsection{Other models of political cognition}

While this paper examined evidence of institutionalization of the topics of public debate, my model may also have implications for a second kind of public opinion institutionalization: the emergence of correlation or constraint (Converse 1964) between positions on logically distant 
topics (e.g., economic redistribution and traditional moral values, Fig. 1). Some recent sociological work explains such cross-domain alignments by positing that respondents organize their views according to broadly shared latent schemas that specify which political positions are consistent with which other ones, and which are opposed (Baldassarri and Goldberg 2014; Hu and Yin 2020; Daenekindt, Koster, and Waal 2017; see also Boutyline 2017; Hunzaker and Valentino 2019). Such an organizing schema consists of "the set of entailments that make certain opinions congruent, or incongruent, with one another" (Baldassari and Goldberg 2014:54-55). For example, imagine one ideological camp that opposes economic redistribution and supports traditional values and another camp supports redistribution and opposes traditional values. The two groups hold no positions in common. Nonetheless, individuals in both camps may structure their views according to the same latent organizing schema where support for economic redistribution is opposed to support for traditional moral values-i.e., supporting one of these issues implies that you oppose the other.

The theory of latent organizing schemas envisions a public opinion field characterized by groups of opponents whose attitudes are mirror opposites of one another. Two such opponents would "appear to agree on what the political debate is about, even if they substantively disagree on which political outcomes are preferable.” (Baldassari and Goldberg 2014:55). This view of "agreement on the terms of disagreement" conflicts with the theoretical model I laid out here, which envisions an unsettled public opinion field where individuals acquire their attitudes from political elites who focus their messaging on popular positions and avoid advertising stances on issues that place them in a minority. Indeed, my analyses demonstrated that individuals at opposed field positions rarely report these positions with the same reliability — a finding which appears at odds with the idea that they hold equal but opposite attitude structures. Rather than 
following inverted versions of the same shared organizing schema, opposing ideological camps may employ separate organizing schemas "that maintain only an indirect, imprecise, symbolic, or accidental opposition to one another" (Boutyline 2017:371).

Indeed, the theoretical model I develop here suggests that individuals may hold consistent attitudes without internalizing any attitude-organizing schemas. The correlations between issue positions held by individuals might simply reflect how these positions are bundled in information streams: for example, if support for gun ownership leads individuals to attend to ideological producers who also oppose immigration, the two positions could come to co-occur in the population without individuals needing to internalize any schema that justifies this organization. In this way, my model is compatible with Martin's (2010) proposal that the organization of cultural elements resides not in the minds of individuals, but in the structure of the environment (see also Foster 2018; Lizardo and Strand 2010). Future work on the cross-domain organization of political attitudes should address the disagreement between these models of public opinion empirically, by examining both the possibility that opposing ideological camps may employ separate attitude-organizing cultural schemas, and the possibility that such schemas may not play any important role in this organization of attitudes.

\subsection{Social networks}

Historically, the study of political communications has seesawed between two complementary theoretical perspectives that respectively foreground (1) direct exposure to elite political messages via mass media, and (2) peer effects that occur when individuals encounter political communications within their social networks (see overviews in Bennett and Iyengar 2008; Bennett and Manheim 2006; Neuman and Guggenheim 2011). While the theoretical model I developed draws on the first perspective, a fuller account of the dynamics of public opinion 
fields also requires attention to the second. For example, networks may provide an alternate mechanism linking position popularity to position reliability: individuals with more popular positions may on the average be more likely to encounter like-minded others, and conversations with these like-minded others may increase the reliability of their shared attitudes. Conversely, networks may also strengthen the key mechanism discussed here. Given high rates of political homophily, personal networks may serve as another diffusion channel via which messages from political elites reach individuals who share their field positions (Druckman, Levendusky, and McLain 2018; Hilbert et al. 2017). Future work should expand the model of public opinion fields to fully theorize the role of social networks.

\subsection{Field Theory of Public Opinion}

Scholars have noted that the language of field theory is useful for integrating distinct disciplinary approaches to studying social life (Beckert 2010; Fligstein and McAdam 2011, 2012). Following broadly in the tradition of these integrative efforts, I used this language to bring together findings from across diverse traditions for studying attitudes and political culture. Translating these descriptions into this common language pointed to new hypotheses at the junctions of these fields of study, both by highlighting connections between different findings and by revealing tensions latent in present work. By linking public opinion to the burgeoning study of social fields, I also hope that this perspective may help reintegrate the study of public opinion_-long a "missing concept" in sociology (Manza and Brooks 2012) — into closer dialog with contemporary sociological theory. 


\section{REFERENCES}

Ackerman, Bruce. 1989. “Why Dialogue?" The Journal of Philosophy 86(1):5-22. doi: $10.2307 / 2027173$

Alwin, Duane 2007. Margins of Error: A Study of Reliability in Survey Measurement. 1st ed. Wiley-Interscience.

Alwin, Duane and Jon Krosnick. 1991. "The Reliability of Survey Attitude Measurement The Influence of Question and Respondent Attributes." Sociological Methods \& Research 20(1):139-81.

Baldassarri, Delia, and Andrew Gelman. 2008. "Partisans without Constraint: Political Polarization and Trends in American Public Opinion.” American Journal of Sociology 114(2):408-46.

Baldassarri, Delia, and Amir Goldberg. 2014. "Neither Ideologues nor Agnostics: Alternative Voters' Belief System in an Age of Partisan Politics.” American Journal of Sociology 120(1):45-95. doi: 10.1086/676042.

Barge, Scott, and Hunter Gehlbach. 2012. "Using the Theory of Satisficing to Evaluate the Quality of Survey Data." Research in Higher Education 53(2):182-200. doi: 10.1007/s11162-011-9251-2.

Bawn, Kathleen, Martin Cohen, David Karol, Seth Masket, Hans Noel, and John Zaller. 2012.

"A Theory of Political Parties: Groups, Policy Demands and Nominations in American Politics." Perspectives on Politics 10(3):571-97.

Beckert, Jens. 2010. "How Do Fields Change? The Interrelations of Institutions, Networks, and Cognition in the Dynamics of Markets." Organization Studies 31(5):605-27. doi:

$10.1177 / 0170840610372184$. 
Bennett, W. Lance, and Shanto Iyengar. 2008. “A New Era of Minimal Effects? The Changing Foundations of Political Communication.” Journal of Communication 58(4):707-31. doi: 10.1111/j.1460-2466.2008.00410.x.

Bennett, W. Lance, and Jarol B. Manheim. 2006. "The One-Step Flow of Communication.” The ANNALS of the American Academy of Political and Social Science 608(1):213-32. doi: $10.1177 / 0002716206292266$.

Bloemraad, Irene, Fabiana Silva, and Kim Voss. 2016. "Rights, Economics, or Family? Frame Resonance, Political Ideology, and the Immigrant Rights Movement.” Social Forces 94(4):1647-74. doi: 10.1093/sf/sov123.

Bode, Leticia, David S. Lassen, Young Mie Kim, Dhavan V. Shah, Erika Franklin Fowler, Travis Ridout, and Michael Franz. 2016. “Coherent Campaigns? Campaign Broadcast and Social Messaging." Online Information Review 40(5):580-94. doi: 10.1108/OIR-112015-0348.

Bonilla, Tabitha, and Justin Grimmer. 2013. "Elevated Threat Levels and Decreased Expectations: How Democracy Handles Terrorist Threats.” Poetics 41(6):650-69. doi: 10.1016/j.poetic.2013.06.003.

Bourdieu, Pierre. 1972. "Public Opinion Does Not Exist." Pp. 124-30 in Communication and Class Struggle. Vol. 1.

Bourdieu, Pierre. 1987. Distinction: A Social Critique of the Judgement of Taste. Harvard University Press.

Boutyline, Andrei. 2017. "Improving the Measurement of Shared Cultural Schemas with Correlational Class Analysis: Theory and Method." Sociological Science 4:353-93. doi: 10.15195/v4.a15. 
Boutyline, Andrei, and Stephen Vaisey. 2017. "Belief Network Analysis: A Relational Approach to Understanding the Structure of Attitudes." American Journal of Sociology 122(5):1371-1447. doi: 10.1086/691274.

Brody, Charles J. 1986. “Things Are Rarely Black and White: Admitting Gray Into the Converse Model of Attitude Stability." American Journal of Sociology 92(3):657-77.

Broockman, David E., and Daniel M. Butler. 2017. "The Causal Effects of Elite Position-Taking on Voter Attitudes: Field Experiments with Elite Communication.” American Journal of Political Science 61(1):208-21. doi: 10.1111/ajps.12243.

Calhoun, Craig J. 1992. Habermas and the Public Sphere. MIT Press.

Carmines, Edward G., and James A. Stimson. 1989. Issue Evolution: Race and the Transformation of American Politics. Princeton University Press.

Carmines, Edward G., and Michael W. Wagner. 2006. "Political Issues and Party Alignments: Assessing the Issue Evolution Perspective.” Annual Review of Political Science 9:67-81.

Chang, Linchiat, and Jon A. Krosnick. 2009. "National Surveys Via Rdd Telephone Interviewing Versus the Internet Comparing Sample Representativeness and Response Quality." Public Opinion Quarterly 73(4):641-78. doi: 10.1093/poq/nfp075.

Cohen, Geoffrey L. 2003. "Party Over Policy: The Dominating Impact of Group Influence on Political Beliefs." Journal of Personality and Social Psychology 85(5):808-22. doi: 10.1037/0022-3514.85.5.808.

Converse, Philip. 1964. "The Nature of Belief Systems in Mass Publics.” in Ideology and Discontent, International yearbook of political behavior research ; v. 5, edited by D. Apter. Free Press. 
Converse, Philip E. 1970. “Attitudes and Non-Attitudes: Continuation of a Dialogue.” The Quantitative Analysis of Social Problems 168:189.

Daenekindt, Stijn, Willem de Koster, and Jeroen van der Waal. 2017. "How People Organise Cultural Attitudes: Cultural Belief Systems and the Populist Radical Right.” West European Politics 40(4):791-811. doi: 10.1080/01402382.2016.1271970.

Daviter, Falk. 2007. "Policy Framing in the European Union." Journal of European Public Policy 14(4):654-66. doi: 10.1080/13501760701314474.

DellaPosta, Daniel. 2020. 'Pluralistic Collapse: The 'Oil Spill' Model of Mass Opinion Polarization." American Sociological Review 85(3):507-36. doi: $10.1177 / 0003122420922989$.

Delli Carpini, Michael X., and Scott Keeter. 1996. What Americans Know about Politics and Why It Matters. New Haven: Yale University Press.

DiMaggio, Paul, Manish Nag, and David Blei. 2013. "Exploiting Affinities between Topic Modeling and the Sociological Perspective on Culture: Application to Newspaper Coverage of U.S. Government Arts Funding.” Poetics 41(6):570-606. doi: 10.1016/j.poetic.2013.08.004.

Druckman, James N., Matthew S. Levendusky, and Audrey McLain. 2018. "No Need to Watch: How the Effects of Partisan Media Can Spread via Interpersonal Discussions." American Journal of Political Science 62(1):99-112. doi: 10.1111/ajps.12325.

Fazio, Russell H. 1995. “Attitudes as Object-Evaluation Associations: Determinants, Consequences, and Correlates of Attitude Accessibility.” Pp. 247-82 in Attitude strength: Antecedents and consequences, edited by R. Petty and J. Krosnick. Lawrence Erlbaum Associates. 
Fligstein, Neil, and Doug McAdam. 2011. “Toward a General Theory of Strategic Action Fields." Sociological Theory 29(1):1-26. doi: 10.1111/j.1467-9558.2010.01385.x.

Fligstein, Neil, and Doug McAdam. 2012. A Theory of Fields. Oxford University Press.

Foster, Jacob G. 2018. “Culture and Computation: Steps to a Probably Approximately Correct Theory of Culture.” Poetics 68:144-54. doi: 10.1016/j.poetic.2018.04.007.

Fowler, Erika Franklin, Michael M. Franz, Gregory J. Martin, Zachary Peskowitz, and Travis N. Ridout. 2021. "Political Advertising Online and Offline.” American Political Science Review 115(1):130-49. doi: 10.1017/S0003055420000696.

Goodman, Leo A. 1974. "The Analysis of Systems of Qualitative Variables When Some of the Variables Are Unobservable. Part I-A Modified Latent Structure Approach.” American Journal of Sociology 79(5):1179-1259. doi: 10.2307/2776792.

Green, Donald, Bradley Palmquist, and Eric Schickler. 2002. Partisan Hearts and Minds: Political Parties and the Social Identity of Voters. Yale University Press.

Groeling, Tim. 2013. "Media Bias by the Numbers: Challenges and Opportunities in the Empirical Study of Partisan News.” Annual Review of Political Science 16(1):129-51. doi: 10.1146/annurev-polisci-040811-115123.

Guess, Andrew M. 2021. “(Almost) Everything in Moderation: New Evidence on Americans’ Online Media Diets." American Journal of Political Science n/a(n/a). doi: 10.1111/ajps.12589.

Habermas, Jurgen. 1991. The Structural Transformation of the Public Sphere: An Inquiry Into a Category of Bourgeois Society. MIT Press.

Hacker, Jacob S., and Paul Pierson. 2014. “After the 'Master Theory’: Downs, Schattschneider, and the Rebirth of Policy-Focused Analysis.” Perspectives on Politics 12(3):643-62. 
Hare, Christopher, and Keith T. Poole. 2014. "The Polarization of Contemporary American Politics.” Polity 46(3):411-29. doi: 10.1057/pol.2014.10.

Hemphill, Libby, and Matthew A. Shapiro. 2019. "Appealing to the Base or to the Moveable Middle? Incumbents' Partisan Messaging before the 2016 U.S. Congressional Elections.” Journal of Information Technology \& Politics 16(4):325-41. doi:

$10.1080 / 19331681.2019 .1651685$.

Henderson, John. 2021. “Downs’ Revenge: How Polarized Candidates Communicate to Voters and Win Elections."

Hilbert, Martin, Javier Vásquez, Daniel Halpern, Sebastián Valenzuela, and Eduardo Arriagada. 2017. “One Step, Two Step, Network Step? Complementary Perspectives on Communication Flows in Twittered Citizen Protests.” Social Science Computer Review 35(4):444-61. doi: 10.1177/0894439316639561.

Hill, Jennifer L. 2001. “An Extension and Test of Converse’s 'Black-and-White' Model of Response Stability." American Political Science Review 95(2):397-413.

Hoffer, Eric. 1951. The True Believer: Thoughts on the Nature of Mass Movements. HarperCollins.

Hoffman, Andrew J. 1999. "Institutional Evolution and Change: Environmentalism and the U.S. Chemical Industry." The Academy of Management Journal 42(4):351-71. doi: $10.2307 / 257008$

Hogg, Michael A. 2000. "Subjective Uncertainty Reduction through Self-Categorization: A Motivational Theory of Social Identity Processes." European Review of Social Psychology 11(1):223-55. doi: 10.1080/14792772043000040. 
Hogg, Michael A. 2004. "Uncertainty and Extremism: Identification with High Entitativity Groups under Conditions of Uncertainty." in The Psychology of Group Perception: Perceived Variability, Entitativity, and Essentialism. Psychology Press.

Holbrook, Allyson, Young IK Cho, and Timothy Johnson. 2006. “The Impact of Question and Respondent Characteristics on Comprehension and Mapping Difficulties." Public Opinion Quarterly 70(4):565-95. doi: 10.1093/poq/nfl027.

Hopkins, Daniel J. 2018. “The Exaggerated Life of Death Panels? The Limited but Real Influence of Elite Rhetoric in the 2009-2010 Health Care Debate." Political Behavior 40(3):681-709. doi: 10.1007/s11109-017-9418-4.

Hout, Michael, Clem Brooks, and Jeff Manza. 1995. "The Democratic Class Struggle in the United States, 1948-1992." American Sociological Review 60(6):805-28. doi: $10.2307 / 2096428$.

Hout, Michael, and Claude S. Fischer. 2002. "Why More Americans Have No Religious Preference: Politics and Generations." American Sociological Review 67(2):165-90. doi: $10.2307 / 3088891$.

$\mathrm{Hu}$, Anning, and Chen Yin. 2020. "Schematic Categorization of Governments Moderates the Association between the Orientation toward Authority and Government Trust in China." Poetics 82:101478. doi: 10.1016/j.poetic.2020.101478.

Hunzaker, M. B. Fallin, and Lauren Valentino. 2019. "Mapping Cultural Schemas: From Theory to Method." American Sociological Review 0003122419875638. doi:

$10.1177 / 0003122419875638$. 
Iyengar, Shanto, and Sean J. Westwood. 2015. "Fear and Loathing across Party Lines: New Evidence on Group Polarization.” American Journal of Political Science 59(3):690-707. doi: 10.1111/ajps. 12152 .

Jepperson, Ronald L. 1991. “Institutions, Institutional Effects, and Institutionalism.” Pp. 143-63 in The New Institutionalism in Organizational Analysis. Vol. 6, edited by W. Powell and P. DiMaggio.

Judd, Charles M., and Jon A. Krosnick. 1982. “Attitude Centrality, Organization, and Measurement." Journal of Personality and Social Psychology 42(3):436-47. doi: 10.1037/0022-3514.42.3.436.

Jungherr, Andreas. 2016. "Twitter Use in Election Campaigns: A Systematic Literature Review." Journal of Information Technology \& Politics 13(1):72-91. doi: 10.1080/19331681.2015.1132401.

Kaminska, Olena, Allan L. McCutcheon, and Jaak Billiet. 2010. "Satisficing Among Reluctant Respondents in a Cross-National Context." Public Opinion Quarterly 74(5):956-84. doi: $10.1093 / \mathrm{poq} / \mathrm{nfq} 062$.

Knobloch-Westerwick, Silvia. 2012. "Selective Exposure and Reinforcement of Attitudes and Partisanship Before a Presidential Election.” Journal of Communication 62(4):628-42. doi: 10.1111/j.1460-2466.2012.01651.x.

Krosnick, Jon A. 1991. "Response Strategies for Coping with the Cognitive Demands of Attitude Measures in Surveys." Applied Cognitive Psychology 5(3):213-36. doi: 10.1002/acp.2350050305.

Krosnick, Jon A. 1999. "Survey Research.” Annual Review of Psychology 50(1):537-67. doi: 10.1146/annurev.psych.50.1.537. 
Laurison, Daniel. 2015. “The Willingness to State an Opinion: Inequality, Don’t Know Responses, and Political Participation.” Sociological Forum 30(4):925-48. doi: 10.1111/socf.12202.

Lizardo, Omar, and Michael Strand. 2010. "Skills, Toolkits, Contexts and Institutions: Clarifying the Relationship between Different Approaches to Cognition in Cultural Sociology." Poetics 38(2):205-28. doi: 10.1016/j.poetic.2009.11.003.

Luker, Kristin. 1985. Abortion and the Politics of Motherhood. University of California Press. Manza, Jeff, and Clem Brooks. 2012. "How Sociology Lost Public Opinion A Genealogy of a Missing Concept in the Study of the Political." Sociological Theory 30(2):89-113. doi: $10.1177 / 0735275112448054$.

Martin, John Levi. 2000. "The Relation of Aggregate Statistics on Beliefs to Culture and Cognition.” Poetics 28(1):5-20. doi: 10.1016/S0304-422X(00)00010-3.

Martin, John Levi. 2003. “What Is Field Theory?” American Journal of Sociology 1-49.

Martin, John Levi. 2010. “Life's a Beach but You're an Ant, and Other Unwelcome News for the Sociology of Culture.” Poetics 38(2):229-44. doi: 10.1016/j.poetic.2009.11.004.

Martin, John Levi, and Matthew Desmond. 2010. "Political Position and Social Knowledge." Sociological Forum 25(1):1-26. doi: 10.1111/j.1573-7861.2009.01154.x.

Martin, John Levi, Adam Slez, and Chad Borkenhagen. 2016. "Some Provisional Techniques for Quantifying the Degree of Field Effect in Social Data.” Socius 2:2378023116635653. doi: $10.1177 / 2378023116635653$.

Mondak, Jeffery J., and Mary R. Anderson. 2004. "The Knowledge Gap: A Reexamination of Gender-Based Differences in Political Knowledge.” Journal of Politics 66(2):492-512. doi: 10.1111/j.1468-2508.2004.00161.x. 
Neiheisel, Jacob R., and Sarah Niebler. 2013. "The Use of Party Brand Labels in Congressional Election Campaigns.” Legislative Studies Quarterly 38(3):377-403.

Nelson, Jacob L. 2020. “The Persistence of the Popular in Mobile News Consumption.” Digital Journalism 8(1):87-102. doi: 10.1080/21670811.2019.1612766.

Nelson, Jacob L., and James G. Webster. 2017. "The Myth of Partisan Selective Exposure: A Portrait of the Online Political News Audience." Social Media + Society 3(3):2056305117729314. doi: 10.1177/2056305117729314.

Neuman, W. Russell, and Lauren Guggenheim. 2011. “The Evolution of Media Effects Theory: A Six-Stage Model of Cumulative Research." Communication Theory 21(2):169-96. doi: 10.1111/j.1468-2885.2011.01381.x.

Nicholson, Stephen P. 2012. "Polarizing Cues." American Journal of Political Science 56(1):5266. doi: 10.1111/j.1540-5907.2011.00541.x.

Perrin, Andrew J., and Katherine McFarland. 2011. "Social Theory and Public Opinion.” Annual Review of Sociology 37(1):87-107. doi: 10.1146/annurev.soc.012809.102659.

Pierson, Paul, and Eric Schickler. 2020. “Madison’s Constitution Under Stress: A Developmental Analysis of Political Polarization.” Annual Review of Political Science 23(1):37-58. doi: 10.1146/annurev-polisci-050718-033629.

Riker, William H. 1993. Agenda Formation. University of Michigan Press.

Roberts, Caroline, Emily Gilbert, Nick Allum, and Léila Eisner. 2019. "Research Synthesis: Satisficing in Surveys: A Systematic Review of the Literature.” Public Opinion Quarterly 83(3):598-626. doi: 10.1093/poq/nfz035.

Roskos-Ewoldsen, David R., Beverly Roskos-Ewoldsen, and Francesca Dillman Carpentier. 2008. "Media Priming: An Updated Synthesis.” Pp. 74-93 in Media Effects. Routledge. 
Russell, Annelise. 2021. “Minority Opposition and Asymmetric Parties? Senators' Partisan Rhetoric on Twitter." Political Research Quarterly 74(3):615-27. doi: $10.1177 / 1065912920921239$.

Savage, Mike, and Elizabeth B. Silva. 2013. "Field Analysis in Cultural Sociology." Cultural Sociology 7(2):111-26. doi: 10.1177/1749975512473992.

Schattschneider, Elmer E. 1975. The Semisovereign People: A Realist's View of Democracy in America. Revised edition. Hinsdale, Ill: Wadsworth Publishing.

Schuman, Howard, and Stanley Presser. 1980. "Public Opinion and Public Ignorance: The Fine Line Between Attitudes and Nonattitudes." American Journal of Sociology 85(5):121425. doi: $10.2307 / 2778897$.

Schuman, Howard, and Stanley Presser. 1996. Questions and Answers in Attitude Surveys: Experiments on Question Form, Wording, and Context. SAGE.

Scott, W. Richard. 1995. "Institutions and Organizations. Foundations for Organizational Science." London: A Sage Publication Series.

Searle, John R. 1980. “The Background of Meaning.” Pp. 221-32 in Speech Act Theory and Pragmatics, Texts and Studies in Linguistics and Philosophy, edited by J. R. Searle, F. Kiefer, and M. Bierwisch. Dordrecht: Springer Netherlands.

Smidt, Corwin D. 2017. "Polarization and the Decline of the American Floating Voter." American Journal of Political Science 61(2):365-81. doi: 10.1111/ajps.12218.

Sniderman, Paul M., and Edward H. Stiglitz. 2012. The Reputational Premium: A Theory of Party Identification and Policy Reasoning. Princeton University Press. 
Stimson, James A., Cyrille Thiébaut, and Vincent Tiberj. 2012. "The Evolution of Policy Attitudes in France." European Union Politics 13(2):293-316. doi: $10.1177 / 1465116512436703$.

Strauss, Claudia. 2012. Making Sense of Public Opinion: American Discourses about Immigration and Social Programs. New York: Cambridge University Press.

Tourangeau, Roger, Lance J. Rips, and Kenneth Rasinski. 2000. The Psychology of Survey Response. Cambridge University Press.

Valentino, Lauren. 2021. "Cultural Logics: Toward Theory and Measurement.” Poetics 101574. doi: 10.1016/j.poetic.2021.101574.

Van Aelst, Peter, Jesper Strömbäck, Toril Aalberg, Frank Esser, Claes de Vreese, Jörg Matthes, David Hopmann, Susana Salgado, Nicolas Hubé, Agnieszka Stępińska, Stylianos Papathanassopoulos, Rosa Berganza, Guido Legnante, Carsten Reinemann, Tamir Sheafer, and James Stanyer. 2017. "Political Communication in a High-Choice Media Environment: A Challenge for Democracy?" Annals of the International Communication Association 41(1):3-27. doi: 10.1080/23808985.2017.1288551.

de Vries, Catherine E., Armen Hakhverdian, and Bram Lancee. 2013. “The Dynamics of Voters' Left/Right Identification: The Role of Economic and Cultural Attitudes*.” Political Science Research and Methods 1(2):223-38. doi: 10.1017/psrm.2013.4.

de Vries, Catherine E., and Sara B. Hobolt. 2012. "When Dimensions Collide: The Electoral Success of Issue Entrepreneurs." European Union Politics 13(2):246-68. doi: $10.1177 / 1465116511434788$.

Weisberg, Herbert F. 2009. The Total Survey Error Approach: A Guide to the New Science of Survey Research. University of Chicago Press. 
Wilderom, Rens, and Alex van Venrooij. 2019. "Intersecting Fields: The Influence of Proximate Field Dynamics on the Development of Electronic/Dance Music in the US and UK." Poetics 77:101389. doi: 10.1016/j.poetic.2019.101389.

Wilson, Anne E., Victoria A. Parker, and Matthew Feinberg. 2020. "Polarization in the Contemporary Political and Media Landscape." Current Opinion in Behavioral Sciences 34:223-28. doi: 10.1016/j.cobeha.2020.07.005.

Wilson, Timothy D., and Sara D. Hodges. 1992. “Attitudes as Temporary Constructions.” Pp. 37-65 in The Construction of Social Judgments.

Yang, Tian, Sílvia Majó-Vázquez, Rasmus K. Nielsen, and Sandra González-Bailón. 2020. "Exposure to News Grows Less Fragmented with an Increase in Mobile Access." Proceedings of the National Academy of Sciences 117(46):28678-83. doi: 10.1073/pnas.2006089117.

Zaller, John, and Stanley Feldman. 1992. “A Simple Theory of the Survey Response: Answering Questions versus Revealing Preferences.” American Journal of Political Science 36(3):579-616. doi: 10.2307/2111583.

Zaller, John R. 1992. The Nature and Origins of Mass Opinion. Cambridge University Press. 


\section{Supplementary materials for "Holding a Position"}

\section{Appendix A. Formal model and estimation strategy}

In this appendix, I formally define the position-holding model, and derive the likelihood function for this model from first principles. This appendix is intended for mathematically-inclined readers who are not already familiar with the formal workings of LCA.

\section{Notation}

I will use the same example as in the main text: the question "do support the death penalty?" (yes/no). I will assume that each of $K$ respondents responded to this question once in each of the three waves $t \in\{1,2,3\}$. I will refer to the set of all possible single-wave answers as $\mathcal{A}=\{y, n\}$, and the set of all possible three-wave answer sequences as

$$
s=\{y y y, n y y, y n y, y y n, y n n, n y n, n n y, n n n\} .
$$

I will refer to the total number of elements in $s$ as $S=|\mathcal{A}|^{\max (t)}$, which in this example equals 8. I will use $s_{i}$ to refer to the $i^{t h}$ element of $s$, and $s_{i t}$ to the $t^{t h}$ element of $s_{i}$, so that, e.g., if $i=$ 2 and $t=1$, then $s_{i}=n y y$ and $s_{i t}=n$. I will designate a respondent's answer sequence across all three waves as $\omega$, and her answer from wave $t$ as $\omega_{t}$. I will call the set of possible positions $\Omega=\{\mathrm{Y}, \mathrm{N}\}$, and the latent position of a given respondent $\tau \in \Omega$.

Since I will frequently reference the probabilities of individual answers (e.g., $P\left(\omega_{t}=y\right)$ or $\left.P\left(\omega_{t}=s_{i}\right)\right)$, three-wave answer sequences (e.g., $\left.P(\omega=y n n)\right)$, and true positions (e.g., $P(\tau=\mathrm{Y}))$, I will generally omit the $\omega_{t}, \omega$, and $\tau$. So, for example, $P(y n y \mid \mathrm{Y})$ stands for $P(\omega=y n y \mid \tau=\mathrm{Y})$, which is the probability that a respondent whose true position is "Yes" answers "yes" on the first and third waves and "no" on the second wave.

Using this notation, the null hypothesis of equal position reliability $\left(H_{0}\right)$ and the alternate hypothesis of unequal reliability $\left(H_{1}\right)$ can be stated as: 


$$
\begin{aligned}
& H_{0}: P(y \mid \mathrm{Y})=P(n \mid \mathrm{N}) \\
& H_{1}: P(y \mid \mathrm{Y}) \neq P(n \mid \mathrm{N})
\end{aligned}
$$

The hypothesis that more popular positions are held more reliably can be rendered (with some simplification) as:

$$
H_{2}: \operatorname{cor}[P(X), P(x \mid X)]>0
$$

\section{Assumptions}

To provide a link between true positions and observed responses, I assume that the respondent whose true attitude is $X$ is more likely to respond with the corresponding answer $x$ than with any other answer:

$$
P(x \mid X)>P(z \mid X) \forall z \neq x
$$

I further describe the intuition behind the linking assumption when introduce it as eq. (1) in the manuscript.

I also make the common latent class assumption that a respondent's answers on two different waves are independent of one another conditional on the respondent's true position,

$$
P\left(\omega_{t} \mid \tau, \omega_{q}\right)=P\left(\omega_{t} \mid \tau\right) \forall q \neq t
$$

\section{Likelihood Function}

My goal is to estimate the above parameters from a contingency table $T$, which cross-tabulates responses across the three waves. Each $T_{i}=\left|s_{i}\right|$ contains the count of respondents whose threewave sequence of answers was $s_{i}$, e.g., $T_{1}=|y y y|$ is the count of respondents answering "yes" on each wave. Assuming independence between respondents, $T$ follows a multinomial distribution with $S$ categories and $K=\Sigma_{i} T_{i}$ trials. Its likelihood function is thus given by

$$
\begin{gathered}
\mathcal{L}(T)=\left(\begin{array}{c}
K \\
|y y y|,|n y y|,|y n y|,|y y n|,|y n n|,|n y n|,|n n y|,|n n n|
\end{array}\right) * \\
P(y y y)^{|y y y|} * P(n y y)^{|n y y|} * P(y n y)^{|y n y|} * P(y y n)^{|y y n|} *
\end{gathered}
$$




$$
P(y n n)^{|y n n|} * P(n y n)^{|n y n|} * P(n n y)^{|n n y|} * P(n n n)^{|n n n|}
$$

This can be rewritten more compactly as

$$
\mathcal{L}(T)=\left(\begin{array}{c}
K \\
T_{1}, \ldots, T_{S}
\end{array}\right) * \prod_{i=1}^{S} P\left(s_{i}\right)^{T_{i}},
$$

where $P\left(s_{i}\right)$ is the probability of a three-wave sequence in $s$ (e.g.,yny). By law of total probability and assumption (A2),

$$
P\left(s_{i}\right)=P(\mathrm{Y}) * P\left(s_{i 1} \mid \mathrm{Y}\right) * P\left(s_{i 2} \mid \mathrm{Y}\right) * P\left(s_{i 3} \mid \mathrm{Y}\right)+P(\mathrm{~N}) * P\left(s_{i 1} \mid \mathrm{N}\right) * P\left(s_{i 2} \mid \mathrm{N}\right) * P\left(s_{i 3} \mid \mathrm{N}\right)
$$

or, more compactly,

$$
P\left(s_{i}\right)=P(\mathrm{Y}) \prod_{t=1}^{\max (t)} P\left(s_{i t} \mid \mathrm{Y}\right)+P(\mathrm{~N}) \prod_{t=1}^{\max (t)} P\left(s_{i t} \mid \mathrm{N}\right)
$$

Finally, combining (A3) and (A4) produces

$$
\mathcal{L}(T)=\left(\begin{array}{c}
K \Sigma_{i} T_{i} \\
T_{1}, \ldots, T_{S}
\end{array}\right) * \prod_{i=1}^{S}\left[P(\mathrm{Y}) \prod_{t=1}^{\max (t)} P\left(s_{i t} \mid \mathrm{Y}\right)+P(\mathrm{~N}) \prod_{t=1}^{\max (t)} P\left(s_{i t} \mid \mathrm{N}\right)\right]^{T_{i}}
$$

Estimation.-My hypotheses concern the probabilities $P(Y), P(N), P(y \mid \mathrm{Y})$ and $P(n \mid \mathrm{N})$.

To arrive at these parameters, I expand and rearrange (A5) as

$$
\begin{array}{r}
\mathcal{L}(T)=\left(\begin{array}{c}
\sum_{i} T_{i} \\
T_{1}, \ldots, T_{8}
\end{array}\right) *\left[P(y \mid \mathrm{Y})^{3} P(\mathrm{Y})+P(y \mid \mathrm{N})^{3} P(\mathrm{~N})\right]^{T_{1}} * \\
*\left(3 *\left[P(y \mid \mathrm{Y})^{2} P(n \mid \mathrm{Y}) P(\mathrm{Y})+P(y \mid \mathrm{N})^{2} P(n \mid \mathrm{N}) P(\mathrm{~N})\right]\right)^{T_{2}+T_{3}+T_{4}} * \\
*\left(3 *\left[P(y \mid \mathrm{Y}) P(n \mid \mathrm{Y})^{2} P(\mathrm{Y})+P(y \mid \mathrm{N}) P(n \mid \mathrm{N})^{2} P(\mathrm{~N})\right]\right)^{T_{5}+T_{6}+T_{7}} * \\
*\left[P(n \mid \mathrm{Y})^{3} P(\mathrm{Y})+P(n \mid \mathrm{N})^{3} P(\mathrm{~N})\right]^{T_{8}} .
\end{array}
$$

The values of $T_{i}$ are observed. The remaining parameters have the constraint

$$
P(\mathrm{Y})+P(\mathrm{~N})=P(y \mid \mathrm{Y})+P(n \mid \mathrm{Y})=P(y \mid \mathrm{N})+P(n \mid \mathrm{N})=1
$$


This leaves three free parameters: $P(\mathrm{Y}), P(y \mid \mathrm{Y})$ and $P(n \mid \mathrm{N})$, which are the parameters needed to test the hypotheses stated above. This model can be estimated from an observed contingency table via approximate maximum likelihood.

Note that, because the ordering of an individual's responses make no difference to the model (e.g., $P(y y n)=P(y n y)=P(n y y))$, the observation counts $T_{2}$ through $T_{7}$ occur in equation (A6) only as the sums $T_{2}+T_{3}+T_{4}$ and $T_{5}+T_{6}+T_{7}$. As a consequence, the degrees of freedom $d f$ available in the data is smaller than the number of cells in $T$. It instead equals the number ways of drawing $\max (t)$ unordered samples with replacement from a set of $|A|$ elements, or

$$
\text { table } d f=\left(\begin{array}{c}
\max (t)+|\mathcal{A}|-1 \\
\max (t)
\end{array}\right)
$$

When $\max (\mathrm{t})=3$, this can be simplified to

$$
\text { table } d f=\frac{1}{6}|\mathcal{A}|(|\mathcal{A}|+1)(|\mathcal{A}|+2)
$$

With two response options $|\mathcal{A}|=|\{y, n\}|=2$, table $d f$ equals 4 , which is exactly enough to estimate the three free parameters in equation (A6).

\section{Generalization}

The above approach can be easily generalized to questions with more answer choices, positions, or panel waves. It is sufficient to set $\mathcal{A}=\{a, b, \ldots, z\}$ and $\Omega=\{A, B, \ldots, Z\}$, and alter $s$ and $\max (t)$ as appropriate. This transforms likelihood function (A5) to

$$
\mathcal{L}(T)=\left(\begin{array}{c}
K \\
T_{1}, \ldots, T_{S}
\end{array}\right) \prod_{i=1}^{S}\left[\sum_{j=1}^{|\Omega|}\left(P\left(\tau_{j}\right) \prod_{t=1}^{\max (t)} P\left(s_{i t} \mid \tau_{j}\right)\right)\right]^{T_{i}}
$$

When the number of panel waves $\max (\mathrm{t})=3$, this likelihood function has $|\Omega||\mathcal{A}|-1$ free parameters, making the overall model degrees of freedom equal 


$$
\text { model } d f=|\Omega| *|\mathcal{A}|
$$

This generalized model can also be estimated from an observed contingency table via maximum likelihood. Note that for the estimation to converge, the number of panel waves $\max (t)$ must be large enough to make table $d f$ (eq. A7) be greater than or equal to model $d f$ (eq. A10).

\section{Estimation Software}

To give myself maximum flexibility while exploring this type of latent class models, I implemented my own estimation software for these models in Python. This software constructs likelihood functions for models like those described in the manuscript, and fits them to observed contingency tables via approximate maximum likelihood using the SciPy implementation of the Cobyla optimization algorithm (Powell 1994, 2007). I used a series of simulations to verify that it can estimate the parameters of interest accurately and without bias. Appendix B describes the simulation procedure and detailed results. (I will make this software freely available upon the manuscript's publication.)

\section{Appendix B. Simulation Tests for Bias and Accuracy in Estimated Probabilities}

To evaluate the accuracy and bias of the estimator for my position-holding model, I examined two different configurations: Configuration 1 simulated variables with two positions and two corresponding responses; and Configuration 2 simulated variables with three positions and three corresponding responses. Each configuration consisted of 10,000 instances of the simulation.

Within each instance, I first generated a random data generating process (DGP), and used the DGP to draw $\mathrm{N}=1,500$ simulated response sequences to a 3-wave survey question. (The full set of simulations thus examined 90 million simulated responses.)

Each simulation instance consisted of the following three steps: (1) I created the DGP by randomly setting the marginal probabilities $P(A), P(B), \ldots, P(Z)$ and corresponding conditional DRAFT ONLY - PLEASE DO NOT CITE WITHOUT PERMISSION 
probabilities $P(a \mid A), P(a \mid B), \ldots, P(z \mid Z)$. I let the marginal and conditional probabilities vary within their full theoretically possible ranges, making sure only that the probabilities satisfy the constraints $P(A)+P(B)+\cdots P(Z)=1, P(a \mid A)+\cdots P(z \mid A)=1$, and $P(x \mid X)>P(y \mid X)$. The DGP represents one survey item. (2) Each draw of the DGP simulates a single survey respondent, and yields a 3-wave sequence of responses to that item. I took $\mathrm{N}=1,500$ draws from this DGP, creating the instance dataset. (3) I fit the position-holding model to the instance dataset, yielding estimates of the simulation parameters. Finally, I added an entry to the configuration-wide dataset to record the true $(P)$ and estimated $(\widehat{P})$ values of each simulation parameter.

After all the simulation instances within the configuration had completed, I analyzed the two resulting configuration-wide datasets. I assessed the bias in parameter estimates for $P(A), P(Z), P(a \mid A)$ and $P(z \mid Z)$ via mean error:

$$
\begin{gathered}
\operatorname{bias}(X)=\operatorname{mean}(P(X)-\hat{P}(X)) \\
\operatorname{bias}(x \mid X)=\operatorname{mean}(P(x \mid X)-\hat{P}(x \mid X))
\end{gathered}
$$

I assessed the accuracy via the correlation between the true and estimated parameter values:

$$
\begin{gathered}
\operatorname{accuracy}(X)=\operatorname{cor}(P(X), \hat{P}(X)) \\
\operatorname{accuracy}(x \mid X)=\operatorname{cor}(P(x \mid X), \hat{P}(x \mid X))
\end{gathered}
$$

\begin{tabular}{lrrrr}
\hline Configuration & $\operatorname{bias}(X)$ & $\operatorname{bias}(x \mid X)$ & $\operatorname{accuracy}(X)$ & $\operatorname{accuracy}(x \mid X)$ \\
\hline Two positions & 0.000 & 0.003 & 0.880 & 0.925 \\
Three positions & 0.001 & -0.002 & 0.852 & 0.929 \\
\hline
\end{tabular}

Appendix Table B1. Bias and accuracy in the estimates of $\mathrm{P}(\mathrm{X})$ and $\mathrm{P}(\mathrm{x} \mid \mathrm{X})$ across the two model configurations. Results from 20,000 simulation runs.

I report these measures in Appendix Table B1. They indicate that the parameter estimates have little or no bias, with $|\operatorname{bias}(X)| \leq 0.001$ and $|\operatorname{bias}(x \mid X)| \leq 0.003$ for both model 
configurations. The estimator is also acceptably accurate, with $\operatorname{accuracy}(X)>0.85$ and $\operatorname{accuracy}(x \mid X)>0.925$ for both model configurations.

\section{Appendix C. Position-level estimates of average occupant reliability}

The regression models discussed in this manuscript analyze the reliability with which individuals hold a position $X$ as a characteristic of that position. However, this reliability may also in part be a characteristic of those individual occupants themselves. To address this confound, it is useful to create a position-level estimate of how reliably the occupants of position $X$ hold all their other positions. So, if $\mathrm{X}$ is a position on question $q$, this estimate will be based on how reliably X's occupants responded to each other question $p \neq q$. This is $\mathbb{E}[$ reliability on other questions $\mid \mathrm{X}]$, which I will call $\mathbb{E}\left[\psi_{R} \mid X\right]$.

To make this exposition easier to follow, I will first describe how to estimate some simpler quantities that are not themselves of direct interest to this paper, beginning with (1) the expected value of a binary trait of a position's occupants, e.g., $\mathbb{E}[$ male $\mid Y]$. I will then extend this approach to (2) the expected value of an integer- or real-valued trait, e.g, $\mathbb{E}[$ age $\mid Y]$. I will then draw on these two procedures to estimate (3) the respondent-level quantity $\psi_{R}(R$ 's average reliability on all other questions,) and finally (4) the position-level quantity of interest, $\mathrm{E}\left[\psi_{R} \mid X\right]$.

\section{Step 1: Position-level estimate of a binary respondent trait}

I will use the example of [male $\mid \mathrm{Y}]$ to show how to calculate the expected value of a binary trait of a position's occupants. If a survey question asked respondents whether they support abortion in cases of risk to life of mother, and "Y" is the "Yes" position, then $\mathbb{E}[$ male $\mid \mathrm{Y}]$ would be the expected sex (percentage male) of those who support abortion in cases of risk to life of mother. 
This can be estimated by repeated application of Bayes rule. Since "male" is a binary variable, $\mathbb{E}[$ male $\mid Y]=1 \times P($ male $\mid Y)$. By Bayes rule,

$$
P(\text { male } \mid Y)=\frac{P(Y \mid \text { male }) P(\text { male })}{P(Y)}
$$

The probability $\mathrm{P}(\mathrm{Y})$ is the chance that a respondent's latent position equals Yes, which is an estimate produced by the position-holding model. P(male) can be estimated directly from the observed frequencies. The remaining probability $P(Y \mid$ male $)$ is the chance that any male respondent's latent position equals Yes. This can be estimated by averaging the estimated probabilities of a Yes position across all male respondents, using the observed response $\omega$ of each respondent $i$ to estimate the probability $\tau=Y$ :

$$
P(Y \mid \text { male })=\frac{\sum_{i} P(\tau=Y \mid \omega) \times \mathrm{m}_{i}}{\sum_{i} \mathrm{~m}_{i}}
$$

Here, $\mathrm{m}_{i}=1$ if $i$ is male, and 0 otherwise. The values of $P(\tau=Y \mid \omega)$ can be calculated by again applying the Bayes rule and expanding the equation, which differs slightly based on the different values of $\omega$. For example, if respondent $i$ has sequence $\omega=y y n$, this probability is given by:

$$
P(\tau=Y \mid y y n)=\frac{P(y y n \mid Y) P(Y)}{P(y y n)}=\frac{P(y \mid Y)^{2} P(n \mid Y) P(Y)}{P(y)^{2} P(n)}
$$

The equations for other values of $\omega$ follow analogous forms.

The position-holding model can provide estimates of $\mathrm{P}(\mathrm{Y}), \mathrm{P}(\mathrm{y} \mid \mathrm{Y})$, and $\mathrm{P}(\mathrm{n} \mid \mathrm{Y})$, while $\mathrm{P}(\mathrm{y})$ and $\mathrm{P}(\mathrm{n})$ can be estimated directly from observed frequencies. Substituting these probabilities into $(\mathrm{C} 3)$ yields the probability that the true position of a respondent with response sequence $y y n$ is $\mathrm{Y}$. I repeat this procedure for each respondent $i$ in the dataset. I then substitute all the resulting values of $P(Y \mid \omega)$ into equation (C2) to get $P(Y \mid$ male), which can finally be substituted into (C1) to calculate the desired quantity $P($ male $\mid Y)$. 


\section{Step 2: Position-level estimate of an integer- or real-valued respondent trait}

This procedure is straightforward to generalize to integer- or real-valued occupant traits by simply summing over all the unique observed values of the trait. For example, the expected age of respondents in the pro-choice position $\mathrm{Y}$ is given by

$$
\mathbb{E}[\text { age } \mid Y]=\sum_{i} a g e_{i} \times P\left(a g e=a g e_{i} \mid Y\right)
$$

Each element in this summation can be estimated via the same steps I used to estimate (C1).

Step 3: Respondent-level estimate of reliability

In this step, I will produce a respondent-level estimate of expected reliability $\psi_{R}$. Note that, due to assumption (1), reliability estimates from two- and three- position models have different ranges. I thus repeat this process separately for two-position and three-position items. For each respondent $R$, $\psi_{R}$ is the estimate of their average reliability on each other item $p \neq q$ they answered (the focal question $q$ is omitted to avoid bias.)

To arrive at $\psi_{R}$, I first calculate the values $\psi_{R, p}$, which is a single-respondent, singlequestion reliability estimate. This is the expected probability that $R$ 's response on wave $t, \omega_{t}$, matches $R$ 's unobservable position $\tau$, given their observed three-wave response sequence $\omega$, or

$$
\psi_{R, p}=\frac{1}{3|\Omega|} \sum_{t=1}^{3} \sum_{\tau \in \Omega}\left[P\left(\tau=\omega_{t} \mid \omega\right)\right]
$$

Each element of the summation $P\left(\tau=\omega_{t} \mid \omega\right)$ can be calculated analogously to (C3). Averaging $\psi_{R, p}$ across all questions $p \neq q$ yields $\psi_{R}$, which is a respondent-level estimate of $R$ 's average reliability on the remaining questions. 
Step 4: Position-level estimate of reliability

The respondent-level estimate of average reliability $\psi_{R}$ is itself a real-valued occupant trait, and can be treated the same way as age in the example above. I can thus use it to finally estimate $\mathbb{E}[$ reliability on other questions $\mid$ position $]=\mathrm{E}\left[\psi_{R} \mid X\right]$ via the same process as $(\mathrm{C} 4)$ above. 
Appendix Table D1. Results from Applying Position-Holding Model to the 2008 - 2010 - 2012 GSS Panel (107 Attitudes).

\begin{tabular}{|c|c|c|c|c|c|c|c|c|c|c|}
\hline \multirow{2}{*}{$\begin{array}{c}\text { GSS } \\
\text { variable }\end{array}$} & & \multicolumn{3}{|c|}{ Positions } & \multirow[b]{2}{*}{$\mathrm{N}$} & \multirow[b]{2}{*}{$\mathrm{P}(\mathrm{A})$} & \multirow[b]{2}{*}{$\mathrm{P}(\mathrm{Z})$} & \multicolumn{3}{|c|}{ Reliability } \\
\hline & & First (A) & (mid) & Last (Z) & & & & $\mathrm{P}(\mathrm{a} \mid \mathrm{A})$ & $\mathrm{P}(\mathrm{z} \mid \mathrm{Z})$ & Diff. \\
\hline absingle & Abortion should be legal when: & ves & & no & 799 & 0.44 & 0.56 & 089 & 0.91 & 0,02 \\
\hline abany & woman wants for any reason & yes & & no & 789 & 0.45 & 0.55 & 0.88 & 0.91 & 0.03 \\
\hline abpoor & low income - can't afford more children & yes & & no & 781 & 0.47 & 0.53 & 0.90 & 0.91 & 0.01 \\
\hline abnomore & married — doesn't want any more children & yes & & no & 780 & 0.47 & 0.53 & 0.91 & 0.90 & -0.01 \\
\hline abdefect & strong chance of serious birth defect & yes & & no & 763 & 0.77 & 0.23 & 0.95 & 0.80 & $-0.15 * * *$ \\
\hline abrape & woman is pregnant as result of rape & yes & & no & 781 & 0.80 & 0.20 & 0.96 & 0.85 & $-0.11 * * *$ \\
\hline abhlth & woman's health is seriously endangered & yes & & no & 767 & 0.91 & 0.09 & 0.97 & 0.78 & $-0.19 * * *$ \\
\hline & Opinion regarding government spending on: & & & & & & & & & \\
\hline natrace & improving the conditions of blacks & too little & $\checkmark$ & too much & 475 & 0.31 & 0.18 & 0.85 & 0.58 & $-0.27 * * *$ \\
\hline natfare & welfare & too little & $\checkmark$ & too much & 552 & 0.22 & 0.40 & 0.74 & 0.84 & $0.10^{*}$ \\
\hline natdrug & dealing with drug addiction & too little & $\checkmark$ & too much & 566 & 0.64 & 0.09 & 0.79 & 0.58 & $-0.21 \#$ \\
\hline natroad & highways and bric & too little & $\checkmark$ & too much & 1220 & 0.47 & 0.11 & 0.82 & 0.57 & $-0.25 * * *$ \\
\hline natsci & suppo & too little & $\checkmark$ & too much & 1124 & 0.40 & 0.11 & 0.74 & 0.66 & -0.08 \\
\hline natcrime & halting the rising crime rate & too little & $\checkmark$ & too much & 573 & 0.61 & 0.05 & 0.83 & 0.57 & $-0.26^{*}$ \\
\hline natcity & solving the problems of the big cities & too little & $\checkmark$ & too much & 486 & 0.43 & 0.17 & 0.78 & 0.55 & $-0.23 \#$ \\
\hline natsoc & social security & too little & $\checkmark$ & too much & 1173 & 0.62 & 0.07 & 0.86 & 0.48 & $-0.37 * * *$ \\
\hline natmass & mass transportation & too little & $\checkmark$ & too much & 1127 & 0.46 & 0.10 & 0.83 & 0.56 & $-0.26 * * *$ \\
\hline natheal & improving and protecting nat's health & too little & $\checkmark$ & too much & 583 & 0.69 & 0.08 & 0.86 & 0.58 & $-0.28 * *$ \\
\hline natpark & recreation & too little & $\checkmark$ & too much & 1231 & 0.30 & 0.04 & 0.75 & 0.68 & -0.08 \\
\hline natspac & oration program & too little & $\checkmark$ & too much & 554 & 0.18 & 0.36 & 0.73 & 0.84 & $0.11 *$ \\
\hline nateduc & improving the nation's education system & too little & $\checkmark$ & too much & 601 & 0.74 & 0.04 & 0.91 & 0.76 & $-0.15 \#$ \\
\hline natarms & the military, armaments and defense & too little & $\checkmark$ & too much & 574 & 0.25 & 0.37 & 0.72 & 0.81 & $0.09 \#$ \\
\hline natchld & assistance for childcare & too little & $\checkmark$ & too much & 1091 & 0.57 & 0.06 & 0.79 & 0.68 & $-0.11 \#$ \\
\hline natenvir & improving and protect the environment & too little & $\checkmark$ & too much & 596 & 0.54 & 0.05 & 0.89 & 0.73 & $-0.16^{*}$ \\
\hline nataid & foreign aid & too little & $\checkmark$ & too much & 546 & 0.14 & 0.51 & 0.47 & 0.92 & $0.45 * * *$ \\
\hline natcityy & assistance to big cities & too little & $\checkmark$ & too much & 503 & 0.21 & 0.39 & 0.69 & 0.74 & 0.06 \\
\hline nathealy & health & too little & $\checkmark$ & too much & 640 & 0.63 & 0.22 & 0.88 & 0.57 & $-0.31 * * *$ \\
\hline natcrimy & law enforcement & too little & $\checkmark$ & too much & 648 & 0.51 & 0.10 & 0.87 & 0.63 & $-0.24 * * *$ \\
\hline nataidy & assistance to other countries & too little & $\checkmark$ & too much & 625 & 0.06 & 0.70 & 0.65 & 0.93 & $0.27 * *$ \\
\hline natfarey & assistance to the poor & too little & $\checkmark$ & too much & 641 & 0.63 & 0.07 & 0.90 & 0.71 & $-0.19 *$ \\
\hline natarmsy & national defense & too little & $\checkmark$ & too much & 620 & 0.27 & 0.36 & 0.76 & 0.78 & 0.01 \\
\hline natenviy & the environment & too little & $\checkmark$ & too much & 636 & 0.64 & 0.13 & 0.89 & 0.64 & $-0.25 * * *$ \\
\hline
\end{tabular}


Holding a Position - Supplementary Materials 12

\begin{tabular}{|c|c|c|c|c|c|c|c|c|c|c|}
\hline \multirow{2}{*}{$\begin{array}{c}\text { GSS } \\
\text { variable }\end{array}$} & & \multicolumn{3}{|c|}{ Positions } & \multirow[b]{2}{*}{$\mathrm{N}$} & \multirow[b]{2}{*}{$\mathrm{P}(\mathrm{A})$} & \multirow[b]{2}{*}{$\mathrm{P}(\mathrm{Z})$} & \multicolumn{3}{|c|}{ Reliability } \\
\hline & & First (A) & (mid) & Last (Z) & & & & $\mathrm{P}(\mathrm{a} \mid \mathrm{A})$ & $\mathrm{P}(\mathrm{z} \mid \mathrm{Z})$ & Diff. \\
\hline nateducy & education & too little & $\checkmark$ & too much & 659 & 0.76 & 0.04 & 0.92 & 0.79 & -0.12 \\
\hline natracey & assistance to blacks & too little & $\checkmark$ & too much & 504 & 0.27 & 0.31 & 0.81 & 0.69 & $-0.12 *$ \\
\hline natdrugy & drug rehabilitation & too little & $\checkmark$ & too much & 589 & 0.45 & 0.15 & 0.83 & 0.66 & $-0.16^{*}$ \\
\hline natspacy & space exploration & too little & $\checkmark$ & too much & 603 & 0.16 & 0.37 & 0.77 & 0.80 & 0.03 \\
\hline & Confidence in people running instutitions: & & & & & & & & & \\
\hline $\begin{array}{l}\text { confinan } \\
\text { conbus }\end{array}$ & $\begin{array}{l}\text { banks \& financial institutions } \\
\text { maior companies }\end{array}$ & $\begin{array}{l}\text { a lot } \\
\text { a lot }\end{array}$ & $\begin{array}{l}\checkmark \\
\checkmark\end{array}$ & $\begin{array}{l}\text { hardly any } \\
\text { hardly any }\end{array}$ & $\begin{array}{l}853 \\
836\end{array}$ & $\begin{array}{l}0.15 \\
0.12\end{array}$ & $\begin{array}{l}0.41 \\
0.22\end{array}$ & $\begin{array}{l}0.49 \\
0.69\end{array}$ & $\begin{array}{l}0.65 \\
0.64\end{array}$ & $\begin{array}{r}0.16 \\
-0.05\end{array}$ \\
\hline conclerg & organized religion & a lot & $\checkmark$ & hardly any & 835 & 0.18 & 0.22 & 0.70 & 0.77 & 0.06 \\
\hline coneduc & education & a lot & $\checkmark$ & hardly any & 857 & 0.28 & 0.18 & 0.63 & 0.60 & -0.03 \\
\hline confed & executive branch & a lot & $\checkmark$ & hardly any & 838 & 0.21 & 0.33 & 0.43 & 0.72 & $0.29 * * *$ \\
\hline conlabor & organized labor & a lot & $\checkmark$ & hardly any & 786 & 0.12 & 0.29 & 0.58 & 0.77 & $0.19 *$ \\
\hline conpress & press & a lot & $\checkmark$ & hardly any & 845 & 0.08 & 0.48 & 0.65 & 0.78 & $0.14^{*}$ \\
\hline contv & teles & a lot & $\checkmark$ & hardly any & 845 & 0.15 & 0.34 & 0.46 & 0.79 & $0.33 * *$ \\
\hline conjudge & Supr & a lot & $\checkmark$ & hardly any & 821 & 0.31 & 0.24 & 0.76 & 0.55 & $-0.21 * *$ \\
\hline consci & scien & a lot & $\checkmark$ & hardly any & 796 & 0.39 & 0.09 & 0.83 & 0.47 & $-0.36 * * *$ \\
\hline conlegis & Cong & a lot & $\checkmark$ & hardly any & 842 & 0.07 & 0.46 & 0.49 & 0.79 & $0.30^{* *}$ \\
\hline conarmy & military & a lot & $\checkmark$ & hardly any & 839 & 0.50 & 0.04 & 0.85 & 0.89 & 0.04 \\
\hline & me and pu & & & & & & & & & \\
\hline courts & with cri & less hrsh & $\checkmark$ & harsher & 1078 & 0.09 & 0.70 & 0.75 & 0.90 & $0.15^{* * *}$ \\
\hline cappun & favor or oppose deat & favor & & oppose & 1154 & 0.68 & 0.32 & 0.92 & 0.88 & $-0.05 * *$ \\
\hline gunlaw & favor or oppose & favor & & oppose & 841 & 0.78 & 0.22 & 0.92 & 0.74 & $-0.18 * * *$ \\
\hline grass & $\begin{array}{l}\text { should marijuana be made legal } \\
\text { Free speech }\end{array}$ & legal & & not legal & 711 & 0.44 & 0.56 & 0.90 & 0.90 & 0.00 \\
\hline spkath & allow anti-religionist to speak & allow & & not allow & 851 & 0.76 & 0.24 & 0.95 & 0.65 & $-0.31 * * *$ \\
\hline colath & allov & allow & & low & 818 & 0.68 & 0.32 & 0.89 & 0.80 & $-0.09 * *$ \\
\hline spkrac & allow & allow & & not allow & 840 & 0.62 & 0.38 & 0.91 & 0.76 & $-0.15 * * *$ \\
\hline colrac & allow & allow & & not allow & 801 & 0.59 & 0.41 & 0.80 & 0.85 & 0.04 \\
\hline librac & allow & allow & & remove & 820 & 0.64 & 0.36 & 0.91 & 0.70 & $-0.21 * * *$ \\
\hline spkcom & allow communist to speak & allow & & not allow & 832 & 0.72 & 0.28 & 0.93 & 0.81 & $-0.11 * * *$ \\
\hline colcom & should communist teacher be $\mathrm{f}$ & fired & & not fired & 781 & 0.31 & 0.69 & 0.80 & 0.86 & 0.06 \\
\hline libcom & allow communists book in library & allow & & remove & 817 & 0.76 & 0.24 & 0.91 & 0.78 & $-0.13 * * *$ \\
\hline spkmil & allow militarist to speak & allow & & not allow & 828 & 0.69 & 0.31 & 0.93 & 0.72 & $-0.21 * * *$ \\
\hline colmil & allow militarist to teach & allow & & not allow & 803 & 0.60 & 0.40 & 0.86 & 0.79 & $-0.07 \#$ \\
\hline spkhomo & allow homosexual to speak & allow & & not allow & 835 & 0.88 & 0.12 & 0.97 & 0.74 & $-0.22 * * *$ \\
\hline
\end{tabular}

DRAFT ONLY - PLEASE DO NOT CITE WITHOUT PERMISSION 
Holding a Position - Supplementary Materials 13

\begin{tabular}{|c|c|c|c|c|c|c|c|c|c|c|}
\hline \multirow{2}{*}{$\begin{array}{c}\text { GSS } \\
\text { variable }\end{array}$} & & \multicolumn{3}{|c|}{ Positions } & \multirow[b]{2}{*}{$\mathrm{N}$} & \multirow[b]{2}{*}{$\mathrm{P}(\mathrm{A})$} & \multirow[b]{2}{*}{$\mathrm{P}(\mathrm{Z})$} & \multicolumn{3}{|c|}{ Reliability } \\
\hline & & First (A) & (mid) & Last (Z) & & & & $\mathrm{P}(\mathrm{a} \mid \mathrm{A})$ & $\mathrm{P}(\mathrm{z} \mid \mathrm{Z})$ & Diff. \\
\hline colhomo & allow homosexual to teach & allow & & not allow & 824 & 0.84 & 0.16 & 0.97 & 0.76 & $-0.20 * * *$ \\
\hline libath & allow anti-religious book in library & allow & & remove & 820 & 0.74 & 0.26 & 0.94 & 0.69 & $-0.25 * * *$ \\
\hline libmil & allow militarists book in library & allow & & remove & 823 & 0.69 & 0.31 & 0.93 & 0.69 & $-0.24 * * *$ \\
\hline libhomo & $\begin{array}{l}\text { allow homosexual's book in library } \\
\text { Gender }\end{array}$ & allow & & remove & 831 & 0.78 & 0.22 & 0.95 & 0.75 & $-0.19 * * *$ \\
\hline fejobaff & support preferential hiring of women & support & & oppose & 350 & 0.32 & 0.30 & 0.61 & 0.82 & $0.21 * *$ \\
\hline discaffm & a man won't get a job or promotion & likely & & unlikely & 372 & 0.09 & 0.22 & 0.47 & 0.39 & -0.09 \\
\hline discaffw & a woman won't get a job or promotion & likely & & unlikely & 439 & 0.17 & 0.02 & 0.72 & 0.71 & 0.00 \\
\hline fepol & women not suited for politics & agree & & disagree & 756 & 0.22 & 0.78 & 0.74 & 0.93 & $0.19^{* * *}$ \\
\hline fehire & should hire and promote $\mathrm{n}$ & agree & $\checkmark$ & disagree & 450 & 0.61 & 0.26 & 0.87 & 0.69 & $-0.18 * *$ \\
\hline meovrwrk & much & agree & $\checkmark$ & disagree & 836 & 0.60 & 0.26 & 0.82 & 0.72 & -0.10 \\
\hline fepresch & presc & agree & & disagree & 823 & 0.07 & 0.12 & 0.44 & 0.65 & 0.20 \\
\hline fefam & nome & agree & & disagree & & 0.02 & 0.19 & 0.80 & 0.70 & -0.10 \\
\hline divlaw & make & easier & $\checkmark$ & more diff. & 751 & 0.32 & 0.49 & 0.79 & 0.82 & 0.03 \\
\hline & Race & & & & & & & & & \\
\hline discaff & are whites hurt by aff. & yes & $\checkmark$ & no & 794 & 0.13 & 0.40 & 0.60 & 0.71 & 0.12 \\
\hline affrmact & $\mathrm{ks}$ & support & & oppose & 756 & 0.09 & 8 & 0.72 & 0.79 & 0.07 \\
\hline racopen & allor & allow & $\checkmark$ & not allow & 852 & 0.25 & 0.73 & 0.69 & 0.88 & $0.18^{* * *}$ \\
\hline wrkwayup & black & agree & $\checkmark$ & disagree & 814 & 0.73 & 0.09 & 0.89 & 0.83 & -0.06 \\
\hline racdifl & differ & yes & & no & 778 & 0.38 & 0.62 & 0.77 & 0.91 & $0.14 * * *$ \\
\hline racdif2 & diffe & yes & & no & 814 & 0.10 & 0.90 & 0.58 & 0.97 & $0.38 * * *$ \\
\hline racdif3 & $n$ & yes & & no & 80 & 0.45 & 0.55 & 0.83 & 0.87 & 0.04 \\
\hline racdif4 & differences due to 1 & yes & & no & 762 & 0.54 & 0.46 & 0.80 & 0.86 & 0.06 \\
\hline & 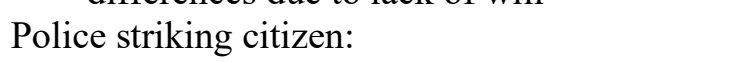 & & & & & & & & & \\
\hline polhitok & 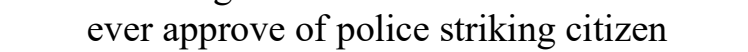 & yes & & no & 358 & 0.70 & 0.30 & 0.93 & 0.76 & $-0.17 * * *$ \\
\hline polabuse & & yes & & no & 815 & 0.07 & 0.93 & 0.57 & 0.95 & $0.38 * * *$ \\
\hline polmurdr & ect & yes & & no & 820 & 0.15 & 0.85 & 0.57 & 0.95 & $0.38 * * *$ \\
\hline polescap & if citi & yes & & no & 793 & 0.73 & 0.27 & 0.91 & 0.68 & $-0.23 * * *$ \\
\hline polattak & $\begin{array}{l}\text { if citizen attacking policeman with fists } \\
\text { Sexuality }\end{array}$ & yes & & no & 838 & 0.89 & 0.11 & 0.95 & 0.56 & $-0.39 * * *$ \\
\hline premarsx & is unmarried sex wrong & wrong & & not wrong & 807 & 0.22 & 0.49 & 0.85 & 0.90 & 0.05 \\
\hline teensex & for teens (14-16) & wrong & & not wrong & 828 & 0.70 & 0.02 & 0.90 & 0.69 & -0.21 \\
\hline homosex & ual sex relations & wrong & & not wrong & 772 & 0.46 & 0.43 & 0.93 & 0.89 & $-0.04 \#$ \\
\hline pillok & teens shld alwys be able to get birth ctrl & agree & & disagree & 367 & 0.14 & 0.21 & 0.79 & 0.60 & -0.19 \\
\hline
\end{tabular}


Holding a Position - Supplementary Materials 14

\begin{tabular}{|c|c|c|c|c|c|c|c|c|c|c|}
\hline \multirow{2}{*}{$\begin{array}{c}\text { GSS } \\
\text { variable }\end{array}$} & & \multicolumn{3}{|c|}{ Positions } & \multirow[b]{2}{*}{$\mathrm{N}$} & \multirow[b]{2}{*}{$\mathrm{P}(\mathrm{A})$} & \multirow[b]{2}{*}{$\mathrm{P}(\mathrm{Z})$} & \multicolumn{3}{|c|}{ Reliability } \\
\hline & & First $(\mathrm{A})$ & (mid) & Last (Z) & & & & $\mathrm{P}(\mathrm{a} \mid \mathrm{A})$ & $\mathrm{P}(\mathrm{z} \mid \mathrm{Z})$ & Diff. \\
\hline pornlaw & pornography should be illegal & illegal & $\checkmark$ & legal & 859 & 0.34 & 0.02 & 0.81 & 0.66 & -0.15 \\
\hline marhomo & $\begin{array}{l}\text { homosexuals should have right to marry } \\
\text { Should government: }\end{array}$ & agree & $\checkmark$ & disagree & 844 & 0.42 & 0.44 & 0.91 & 0.88 & $\begin{array}{r}-0.02 \\
0.00\end{array}$ \\
\hline helpnot & do more, or leave to indiv's $\&$ business & yes & $\checkmark$ & no & 802 & 0.24 & 0.33 & 0.67 & 0.74 & 0.07 \\
\hline eqwlth & 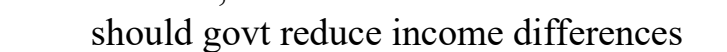 & yes & $\checkmark$ & no & 850 & 0.41 & 0.35 & 0.81 & 0.77 & -0.04 \\
\hline helppoor & $\mathrm{s}$ & ye & $\checkmark$ & $\mathrm{n}$ & 813 & 0.31 & 0.30 & 0.69 & 0.76 & 0.06 \\
\hline helpsick & sl & yes & $\checkmark$ & $\mathrm{n}$ & 813 & 0.41 & 0.18 & 0.85 & 0.76 & -0.08 \\
\hline helpblk & $\begin{array}{r}\text { shou } \\
\text { Right to }\end{array}$ & yes & $\checkmark$ & no & 799 & 0.15 & 0.47 & 0.71 & 0.88 & $\begin{array}{l}0.16^{* *} \\
0.00\end{array}$ \\
\hline suicide1 & 1. & yes & & $\mathrm{n}$ & 776 & 0.62 & 0.38 & 0.91 & 0.86 & $-0.05 *$ \\
\hline suicide2 & if & yes & & no & 814 & 0.11 & 0.89 & 0.75 & 0.96 & $0.21 * * *$ \\
\hline suicide3 & aily & yes & & no & 815 & 0.14 & 6 & 0.66 & 0.97 & $0.31 * * *$ \\
\hline suicide4 & & yes & & no & 799 & 0.20 & 0.80 & 0.74 & 0.95 & $0.21 * * *$ \\
\hline letdie1 & $\begin{array}{l}\text { allow incurable patients to die } \\
\text { sc. }\end{array}$ & yes & & no & 351 & 0.70 & 0.30 & 0.92 & 0.76 & $-0.16 * * *$ \\
\hline prayer & bible prayer in pu & appro & & disapp & 780 & 0.43 & 0.57 & 0.81 & 0.89 & $0.08 * *$ \\
\hline letin1 & number of immigrants to U.S. should b & increased & $\checkmark$ & reduced & 811 & 0.09 & 0.50 & 0.68 & 0.86 & $0.18^{* *}$ \\
\hline uswary & expect U.S. in a world war in 10 years & yes & & no & 373 & 0.53 & 0.47 & 0.87 & 0.81 & -0.06 \\
\hline
\end{tabular}

NOTE.-Check mark $(\checkmark)$ between first and last positions indicates that the variable was coded as 3-position. All variables with 4 or more levels were collapsed to 4 levels if the number of levels was even, and to 3 if it was odd. The "Diff." column equals $P(z \mid Z)$ - $P(a \mid A)$. Its significance is ${ }^{* * *} \mathrm{p}<0.001,{ }^{* *} \mathrm{p}<0.01,{ }^{*} \mathrm{p}<0.05$, \# $\mathrm{p}<0.10$, as determined by likelihood ratio test versus $\mathrm{H}_{0}: \mathrm{P}(\mathrm{a} \mid \mathrm{A})=\mathrm{P}(\mathrm{z} \mid \mathrm{Z})$. The mean absolute difference across the whole table equals 0.14 . 


\section{Appendix E. Robustness tests for cross-subfield alignments}

The position-level dataset used in these regression analyses comes from a set of survey items with non-nested patterns of non-independence. This non-independence is partly the result of the survey instrument, where some items are designed to tap closely related attitudes, and effects of phrasing and question ordering can also induce correlations. It is also partly due to nonindependence within the structure of the public opinion field itself, where cross-subfield alignments induce correlations across different attitudes. From the perspective of this positionlevel dataset, which contains two observations per survey item, this creates a problem of multiple counting: while some public opinion subfields may correspond to a single survey item and thus appear only once, others may recur repeatedly in the guise of seemingly different questions and thus be counted multiple times (hereafter, I will call this “field repetition”). My regression analyses may thus be assigning undue weight to those subfield positions that recur in the guise of different survey items.

In this appendix, I first use observation weights to decrease the impact of high-repetition fields on the regression estimates (tests 1 and 2). I then perform power analyses to examine whether the substantive effects would remain statistically significant if the effective power was reduced to a much smaller $N$ (test 3 ). To preview, results of test 1 and 2 indicate that even aggressive weighting does not substantively affect the estimated effect of popularity on reliability. Results of test 3 indicate that the estimated effect of popularity would remain highly significant even if the $N$ were reduced to less than quarter of their current value (with or without the observation weights). 


\section{Observation weights}

Test 1.- I first calculated regression weights based on the average absolute polychoric correlations between an attitude $i$ and each of the $k-1$ other attitudes $j$ in the data, $\overline{r_{i}}=$

$\frac{1}{k-1} \sum_{j}\left|r_{i j}\right|$, which is a simple and frequently used measure of interdependence or "constraint" between issue positions (e.g., Converse 1964). I weighted each attitude by the inverse of this quantity, $w_{1}(i)=1 / \overline{r_{i}}$. This yielded a set of observation weights in the range $(3.76,16.37)$, meaning that the most constrained attitudes were given roughly $1 / 4$ as much weight as the most independent ones. I applied these weights to each of the models reported in Tables 1 and 2. I found that this had only minor effects on the estimated coefficients, with the effect of popularity on reliability remaining statistically significant at $p<0.0001$ and substantively unchanged.

Test 2.- I calculated the second set of weights within the framework of exploratory factor analysis, where the true subfields correspond to latent factors. I used maximum-likelihood factor analysis of the polychoric correlation matrix to fit a model with 72 orthogonal factors, which is the most that could be successfully estimated from these data. I observed that, if a piece of variance captured by factor $j$ occurs primarily in variable $i$ and rarely recurs in the other variables, then $\lambda_{i j}^{2} / S S_{j} \approx 1$, where $S S_{j}=\Sigma_{j} \lambda_{i j}^{2}$ is $j$ 's sum of squared loadings. Conversely, if $j$ accounts for nearly all the variance in many distinct variables, then any one $\lambda_{i j}^{2} / S S_{j} \approx 1 / n \ll 1$. I thus took the decomposition of $\operatorname{Var}(i)=1$ into $i$ 's communality and uniqueness, $1=\sum_{j} \lambda_{i j}^{2}+$ $u_{i}^{2}$, and used $\lambda_{i j}^{2} / S S_{j}$ to weight each summation element, yielding $w_{2} \in(0,1]$ :

$$
w_{2}(i)=\sum_{j}\left(\frac{\lambda_{i j}^{2}}{S S_{j}}\right) \lambda_{i j}^{2}+1 \times u_{i}^{2}=\sum_{j}\left(\frac{\lambda_{i j}^{4}}{S S_{j}}\right)+u_{i}^{2} .
$$

This produced weights in the range $(0.013,0.063)$, meaning the variables with the most recurrent variance were given roughly $1 / 5$ as much weight as the the least recurrent ones. Using this set of DRAFT ONLY - PLEASE DO NOT CITE WITHOUT PERMISSION 
weights again had only minor effects on coefficient estimates, with the estimated effect of popularity remaining significant at $p<0.0001$.

\section{Power analyses}

Test 3.-The analyses in the main manuscript are currently based on sets of $N_{2}=104$ positions from two-category items, and $N_{3}=110$ positions from three-category items. These $N$ may be larger than the true number of separate field positions. I thus performed power analyses to examine what consequences reducing this $N$ would have on the statistical significance of the coefficient for popularity in Tables 1 and 2. The true number of field positions is unobservable. To get a sense for the alternate sample sizes $\left(N_{2}^{*}, N_{3}^{*}\right)$ to use in the power analyses, I first used two different approaches to arrive at two rough heuristic estimates for these quantities, $\left(N_{2}^{\prime}, N_{3}^{\prime}\right)$ and $\left(N_{2}^{\prime \prime}, N_{3}^{\prime \prime}\right)$. For a more conservative test, I then set $N_{2}^{*}=\frac{1}{4} N_{2}$ and $N_{3}^{*}=\operatorname{round}\left(\frac{1}{4} N_{3}\right)$, which is below both $\left(N_{2}^{\prime}, N_{3}^{\prime}\right)$ and $\left(N_{2}^{\prime \prime}, N_{3}^{\prime \prime}\right)$.

I based the first estimate of $N_{2}^{\prime}$ and $N_{3}^{\prime}$ on a count of factors and uniquenesses produced through exploratory factor analysis. Within each set of items, I calculated $N^{\prime}=2(f+q)$, where $f$ is the number of orthogonal factors with $S S>1$ and $q=\left\lfloor\sum_{i} u_{i}^{2}\right\rfloor$ is the rounded sum of the uniquenesses left over from fitting an $f$-factor model to the polychoric correlation matrix $(f+q$ is doubled because each field corresponds to two positions.) This yielded $f_{2}=10, f_{3}=16, q_{2}=$ $21, q_{3}=23, N_{2}^{\prime}=62$ and $N_{3}^{\prime}=78$.

The GSS codebook classifies each item as belonging to up to three major subject categories, ${ }^{1}$ which range from very broad ("USA," "women”) to relatively specific ("birth control," "divorce.") I created the second pair of heuristic estimates $\left(N_{2}^{\prime \prime}\right.$ and $\left.N_{3}^{\prime \prime}\right)$ on the basis of

\footnotetext{
${ }^{1} \mathrm{I}$ am referring to the major (bolded) subject headings in Appendix V, available online at http://gss.norc.org/documents/codebook/GSS_Codebook_AppendixV.pdf.
}

DRAFT ONLY - PLEASE DO NOT CITE WITHOUT PERMISSION 
these classifications, using the total count of unique subject categories of the items in each set as a proxy for the number of subfields, and then doubling it to arrive at the number of positions. This yielded $N_{2}^{\prime \prime}=42$ and $N_{3}^{\prime \prime}=50$.

For a more conservative test, I finally performed the power analyses using $N_{2}^{*}=26=$

$\frac{1}{4} N_{2}$ and $N_{3}^{*}=28 \approx \frac{1}{4} N_{3}$, which are below both of the above estimates. I estimated the statistical significance of popularity in Models 1 and 2 in Tables 1 and 2 of the manuscript using these alternate sample sizes (it is not possible to do the same for Model 3 because it contains $N / 2$ item fixed effects, and thus requires more degrees of freedom than available with $N^{*}$.) I then repeated the same power analysis using each set of regression weights calculated in tests 1 and 2 above. In all twelve cases, I found that the effect of popularity on reliability remained highly significant at $p<0.0001$.

\section{Appendix F. Simulation Tests for Bias in Estimated Effect of Popularity on Reliability}

In the primary analyses, I found that the popularity of a position $P(X)$ has a strong positive estimated effect on its reliability $P(x \mid X)$. Here, I examine whether this estimated effect of popularity (hereafter, $\beta$ ) could be due to a bias in the position-holding model estimates. Though the analyses I reported in Appendix B indicated that the univariate estimates of $P(X)$ and $P(x \mid X)$ are unbiased, there may nonetheless be a bias in the estimates of their bivariate distribution. This could then lead to a bias in the regression estimates of the effect of popularity on reliability, $\operatorname{bias}(\beta)$. Here, I will reanalyze the 20,000 simulation runs from Appendix B to estimate $\operatorname{bias}(\beta)$. I will then assess whether $\operatorname{bias}(\beta)$ could account for the estimated effect of popularity in Model $\mathrm{A}$ in Tables 2 and 3, $\beta_{\widehat{o b s}}$. 
To search for possible bias in $\beta$, I first apply Model A to each of the two configurationwide datasets from Appendix B, using the estimated values of position popularity $\hat{P}(X)$ and reliability $\hat{P}(x \mid X): \hat{P}(x \mid X)=\beta_{\text {sิm }} * \hat{P}(X)+\alpha$. I then fit the same model to the true popularity and reliability parameters from these simulations: $P(x \mid X)=\beta_{\operatorname{sim}} * P(X)+\alpha$. Finally, I use the estimated popularity effects from these models $\left(\beta_{\widehat{s} \widehat{m}}\right.$ and $\left.\beta_{\text {sim }}\right)$ to estimate the bias of interest:

$$
\operatorname{bias}(\beta)=\beta_{\widehat{s i m}}-\beta_{\text {sim }}
$$

As Appendix Table F1 indicates, the slope estimates for two-position simulations were $\beta_{\text {s } \widehat{l m}}=0.024$ and $\beta_{\text {sim }}=0.004$, thus yielding $\operatorname{bias}(\beta)=+0.020$. Since $\operatorname{bias}(\beta)>0$, the twoposition model may indeed overestimate the effect of popularity on reliability. However, comparing bias $(\beta)=+0.020$ to $\beta_{\widehat{o b s}}=0.375$ indicates that such a bias would account for only roughly $5 \%$ of the empirically observed effect of popularity on reliability in the two-position model. Thus, though these results suggest that the true effect of popularity for two-position models may be slightly smaller than estimated, it leaves the substance of the conclusion unchanged.

\begin{tabular}{lcccc}
\hline Configuration & $\beta_{\text {sิm }}$ & $\beta_{\text {sim }}$ & $\beta_{\text {ô } s}$ & bias $(\beta)$ \\
\hline Two positions & 0.024 & 0.004 & 0.375 & +0.020 \\
Three positions & -0.035 & -0.012 & 0.429 & -0.023 \\
\hline
\end{tabular}

Appendix Table F1. Examination of Possible Bias in the Estimated Effects of Popularity on Reliability. The first three columns contain regression slopes produced by fitting Model A: (i) to estimates of popularity and reliability produced from 20,000 simulation runs $\left(\beta_{s \widehat{s m}}\right)$; (ii) to the corresponding true population parameters from these simulation runs $\left(\beta_{\text {sim }}\right)$; and (iii) to the estimates of popularity and reliability produced from observed data $\left(\beta_{\widehat{o b s}}\right.$; from Tables 2 and 3.) The remaining column is the estimated $\operatorname{bias}(\beta)=\beta_{\text {sim }}-\beta_{\text {sim }}$.

Turning to the three-position simulations, I find that $\beta_{\widehat{s i m}}=-0.035$ and $\beta_{\text {sim }}=-0.012$, yielding $\operatorname{bias}(\beta)=-0.023$. Since this estimated bias is negative (i.e., conservative), it cannot 
account for any of the observed effect of popularity on reliability in the three-position model $\left(\beta_{\widehat{o b s}}=0.429.\right)$ Rather, this result suggests that the true effect of popularity for two-position model may be slightly larger than reported in Table 3 - but again, the difference is too small to affect substantive interpretation. Thus, overall, the analyses in this appendix did not reveal any estimator bias that could account for the observed effect of popularity in reliability.

\section{Appendix G. Simulations with Continuous Latent Positions}

I designed an additional simulation framework to rule out the possibility that the results I report here could be (i) an artifact of regression to the mean or (ii) an artifact of binarization. In this framework, each simulation has three primary components:

A. Random variable $L$ that yields the true latent position $L_{i}$ of each respondent $i$. Depending on the scenario examined in the simulation, $L$ can either be a "genuine" continuous random variable that assigns different latent positions to different $i$, or it can be a constant that always yields the same true position for all $i$. In either case, each respondent's $L_{i}$ is drawn from $L$ at wave 1 and then remains fixed across the waves.

B. Continuous random variable $E$ that yields' their response error $E_{i}$. The error varies across waves, so each respondent $i$ 's continuously-valued response on wave $t$ equals $x_{i t}=L_{i}+E_{i t}$

C. A discretization function $c_{2}\left(x_{i t} ; q_{1}\right): \mathbb{R} \rightarrow\{\mathrm{a}, \mathrm{z}\}$ or $c_{3}\left(x_{i t} ; q_{1}, q_{2}\right): \mathbb{R} \rightarrow\{\mathrm{a}, \mathrm{v}, \mathrm{z}\}$ that transforms the continuously-valued response of respondent $i$ on wave $t$ into the choice of one of two or three possible responses to a survey item, respectively. The discretization functions can be defined by specifying the cutpoint(s) $q$, i.e.: 
$c_{2}\left(x ; q_{1}\right)=\left\{\begin{array}{ll}a & \text { for } x<q_{1} \\ z & \text { for } x \geq q_{1}\end{array} \quad\right.$ and $\quad c_{3}\left(x ; q_{1}, q_{2}\right)=\left\{\begin{array}{rr}a & \text { for } x<q_{1} \\ v & \text { for } q_{1} \leq x \leq q_{2} \\ z & \text { for } x>q_{2}\end{array}\right.$ where ' $a$ ' and ' $z$ ' respectively represent the leftmost and rightmost response to a survey item (whether 2- or 3-category), and ' $v$ ' represents the neutral response to a 3category item.

\section{Simulation S1. Regression to the mean.}

I first explore a scenario that features regression to the mean. For simplicity, I focus on a twocategory item with response categories $a$ and $z$. All simulated respondents have the same latent position, which (in the absence of response error) corresponds to response category $a$. Their response on wave $t$ then depends on their draw from the error distribution $E$. If their draw is near the mean/mode of the error distribution, they correctly report $a$. Respondents in this scenario only report $z$ if their draw from the error distribution was unusually high. This scenario thus has two important properties: first, response $a$ would be far more popular than $z$. And second, picking response $z$ on wave $t$ would most frequently be followed by picking response $a$ on wave $t+1$. Thus, by construction, less popular responses would be generally less reliable due to regression to the mean. I use this simulation to ask whether such a process could have generated the results I observed in the manuscript.

For simplicity, I complete the formalization of this scenario as follows. I use a simple discretization function $c_{2}$ with $q_{1}=0.5$ as its cutpoint. The respondents' true latent attitudes $L$ are then identical and fixed at a constant value of $x<0.5$. Response error $E_{i t}$ is drawn from a Normal distribution with a mean of 0 and a standard deviation of $s$. To yield the intended scenario, $x$ and $s$ need to be adjusted so that two conditions are met: (i) even though all respondents' true position corresponds to response category $a$, a non-trivial number of 
respondents should still answer $z$; but (ii) the number that answer $a$ should nonetheless be meaningfully larger than the number that answer $z$. The results I present below come from a simulation with $L=x=0.4$ and $s=0.5$, though all other values of $L$ and $s$ I examined have yielded the same conclusions as long as they fulfilled conditions (i) and (ii) above. I will refer to this simulation as S1. It is depicted graphically in Figure G1.

True position: constant $\{$ ' $x$ ': 0.4$\}$

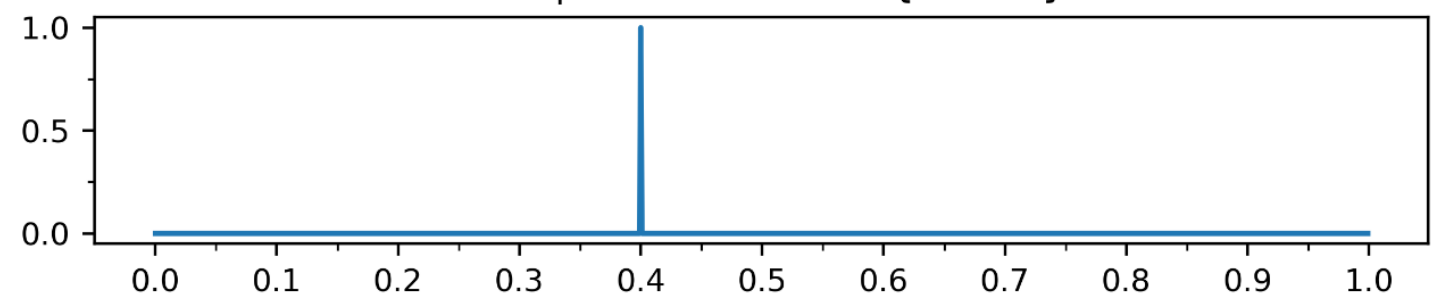

Response error: Normal \{'center': 0, 'sd': 0.5$\}$
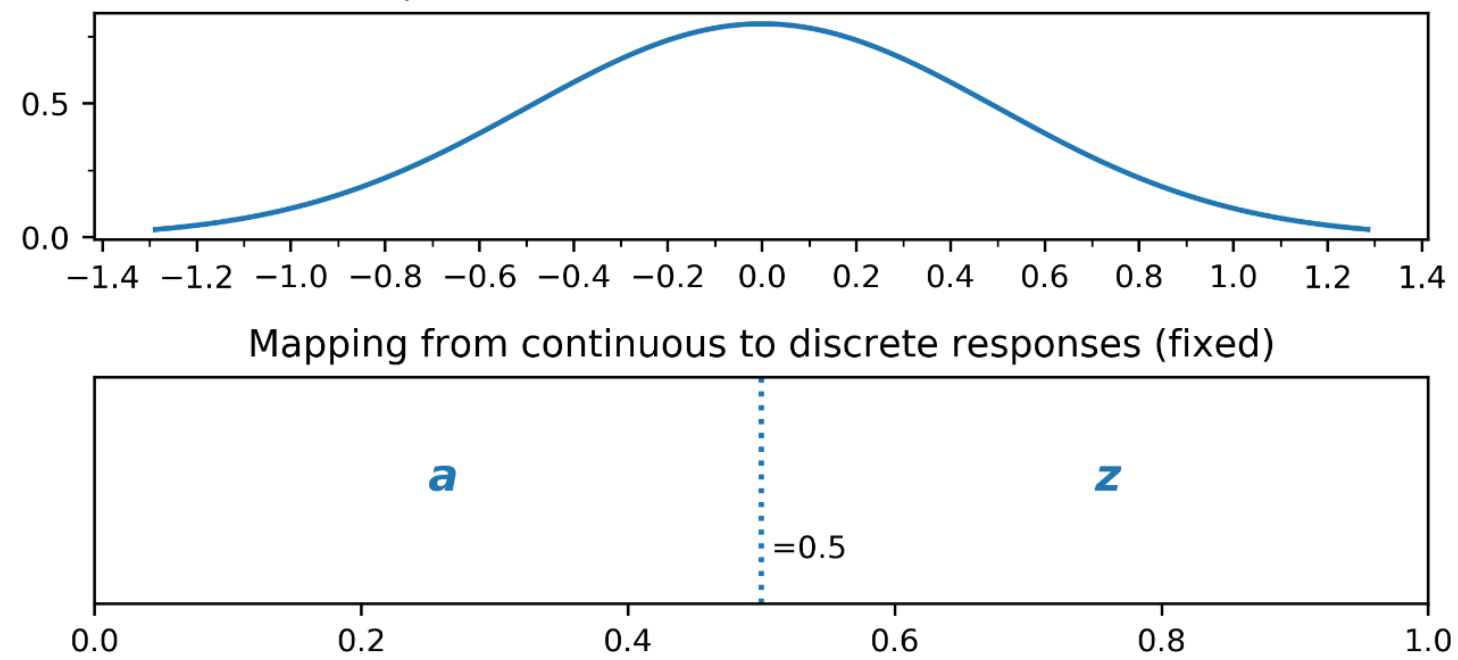

Figure G1. Simulation S1. Fixed true position $L=0.4$ and response error $E_{i j} \sim N(0,0.5)$.

I simulated 1000 survey items that follow scenario $S 1$, with $\mathrm{N}=1500$ simulated respondents each. Simulation S1 was designed to yield a positive correlation between $\mathrm{P}(\mathrm{X})$ and $\mathrm{P}(\mathrm{x} \mid \mathrm{X})$, And indeed, the results of simulation $\mathrm{S} 1$ indicate a positive correlation: 
$\operatorname{corr}(P(X), P(x \mid X))=0.67$. This is comparable to the main correlation I observed in the manuscript, where $\operatorname{corr}(P(X), P(x \mid X))=0.78$.

Could the main correlation in the manuscript have come from a process like the one simulated in scenario S1? A close examination of the results indicates that it could not. The mismatch between observed and simulated results becomes clear if we examine the majority positions $A$ and minority position $Z$ separately from one another. This disaggregates $\operatorname{corr}(P(X), P(x \mid X))$ into its two constituent correlations, $\operatorname{corr}(P(A), P(a \mid A))$ and $\operatorname{corr}(P(Z), P(z \mid Z))$. In simulation $\mathrm{S} 1$, this disaggregation makes the positive correlation between popularity and reliability disappear. Indeed, even though in $\mathrm{S} 1, \operatorname{corr}(P(X), P(x \mid X))=$ 0.67, its two constituent components in the simulation were both negative:

$\operatorname{corr}(P(A), P(a \mid A))=-0.89$ and $\operatorname{corr}(P(Z), P(z \mid Z))=-0.06^{2}$

To compare this with the observed results, I recoded the GSS data so that the majority position is always A and the minority position $\mathrm{Z}$. Much as in simulation S1, the observed correlation is high and positive: $\operatorname{corr}(P(X), P(x \mid X))=0.78$. However, unlike in the simulation, disaggregation does not make this result disappear. Indeed, with observed data, the two constituent correlations are also high and positive: $\operatorname{corr}(P(A), P(a \mid A))=0.79$ and $\operatorname{corr}(P(Z), P(z \mid Z))=0.60 .{ }^{3}$ In other words, with models estimated from real GSS data, higher position popularity was associated with higher position reliability even if we look at only the minority positions (or only the majority positions) in isolation. This clearly indicates that the

\footnotetext{
${ }^{2}$ The exact value of $\operatorname{corr}(P(X), P(x \mid X))$ varied based on the specific combination of the $\mathrm{L}$ constant the error variance $s$. However, in all the combinations I examined, $\operatorname{corr}(P(X), P(x \mid X))$ always broke down into two starkly different correlations: the first high and negative, and the second either weakly negative or weakly positive.

${ }^{3}$ This correlation is across all items. For 2-category items, $\operatorname{corr}(P(X), P(x \mid X))=0.846, \operatorname{corr}(P(A), P(a \mid A))=$ 0.593 and $\operatorname{corr}(P(Z), P(z \mid Z))=0.704$. For 3-category items, $\operatorname{corr}(P(X), P(x \mid X))=0.676$, $\operatorname{corr}(P(A), P(a \mid A))=0.682$ and $\operatorname{corr}(P(Z), P(z \mid Z))=0.301$.
}

DRAFT ONLY - PLEASE DO NOT CITE WITHOUT PERMISSION 
correlation observed in the main analyses is not due to the same data generating process as the result in scenario S1.

Another sign that the model's simulated behavior here is categorically different from observed cases comes from the position-holding model's likelihood function. Note that, in Simulation S1, all responses " $z$ " are error responses from respondents whose true position is A; that is, no simulated respondents truly hold position $\mathrm{Z}$. The conditional probability $\mathrm{P}(\mathrm{z} \mid \mathrm{Z})$ is thus undefined. And indeed, if we examine the model estimates from simulation S1, we can see that the position-holding model usually cannot find a satisfactory value of $\mathrm{P}(\mathrm{z} \mid \mathrm{Z})$ : in $84 \%$ of the S1 simulation runs, the model estimates that $\mathrm{P}(\mathrm{z} \mid \mathrm{Z})=0.5$, which is the smallest possible value that $\mathrm{P}(\mathrm{x} \mid \mathrm{X})$ can take in a 2-category model. In contrast, with the 119 actual GSS items analyzed in this manuscript, the position-holding model never found that the maximum likelihood lies at either extreme of $\mathrm{P}(\mathrm{z} \mid \mathrm{Z})$ 's or $\mathrm{P}(\mathrm{a} \mid \mathrm{A})$ 's range. This degenerate model behavior with simulated data - but not the true GSS data - further suggests that the true GSS data was not produced by a data generating process like the one in scenario $\mathrm{S} 1$.

\section{Simulation S2. Discretization.}

I also explore the possibility that the observed results may be an artifact of the binarization of a unimodal, strongly right-skewed distribution of true attitudes that is binarized around the cutpoint $q_{1}=0.5$. In such a configuration, the average attitude of respondents whose position corresponds to $a$ would be much further from the cutpoint than the true attitude of respondents whose position corresponds to $z$ (see figure G2). All respondents have identical symmetrical error functions centered at 0 . 
In this scenario, respondents in position $A$ may appear more reliable than those in $Z$ simply because it requires a greater amount of error for respondents in $A$ to incorrectly report $z$ than it does for respondents in $Z$ to report $a$. To simulate this second class of scenarios (S2), I use the $\operatorname{Beta}(2,6)$ distribution to generate respondent position $L$. As desired, this distribution is unimodal and strongly right-skewed. I use the same error function $\mathrm{E}$ and the same discretizer $c_{2}$ as in scenario $\mathrm{S} 1$. This scenario is summarized in figure $\mathrm{G} 2$.

\section{True position: Beta $\{$ 'a': 2, 'b': 6\}}

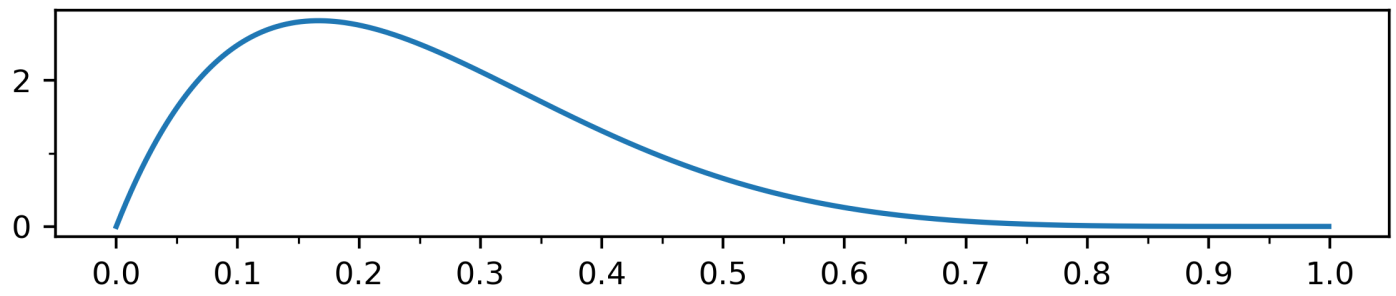

Response error: Normal \{'center': 0, 'sd': 0.5$\}$

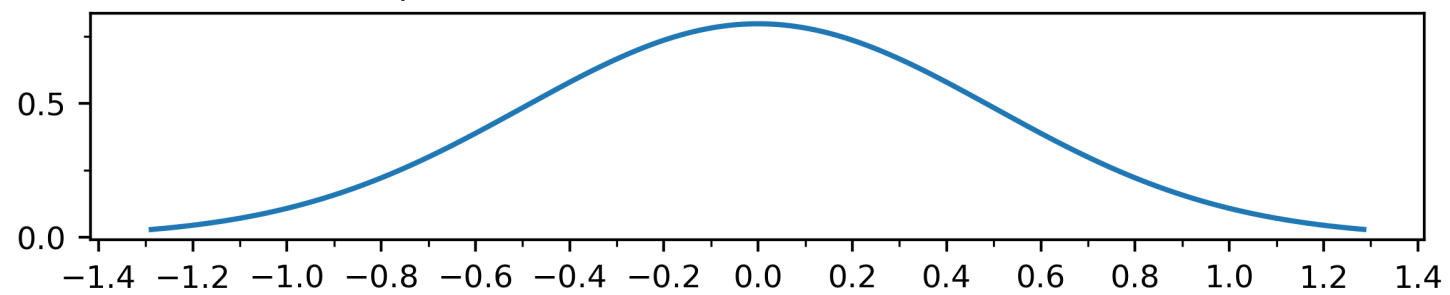

Mapping from continuous to discrete responses (fixed)

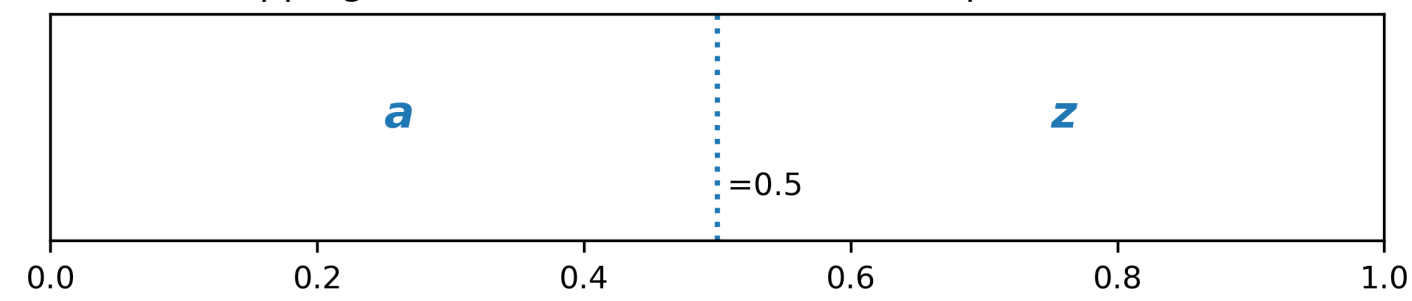

Figure G2. Simulation S2 with true position $L \sim \operatorname{Beta}(2,6)$ and response error $E_{i j} \sim N(0,0.5)$.

I simulated 500 survey items that follow scenario S2 (with $\mathrm{N}=1500$ respondents each), and then estimated my position-holding model from the resulting dataset. My simulation results were substantively identical to the ones yielded by scenario S1 above. Specifically, as with 
scenario S1 above, simulation S2 again yielded a positive correlation between position popularity and reliability: $\operatorname{corr}(P(X), P(x \mid X))=0.745$. Once again, this is comparable to the main correlation I observed in the manuscript, where $\operatorname{corr}(P(X), P(x \mid X))=0.803$. However, just as with the scenario $\mathrm{S} 1$, disaggregating $\operatorname{corr}(P(X), P(x \mid X))$ into separate correlations for minority and majority positions makes this strong positive correlation disappear: in scenario S2, $\operatorname{corr}(P(A), P(a \mid A))=-0.66$ and $\operatorname{corr}(P(Z), P(z \mid Z))=-0.89$. As I noted above, this contrasts greatly with the results I obtained from the GSS data, where the strong positive correlation was in place for both the minority and the majority positions.

Simulations S3 - S6. Additional tests.

To ascertain that the findings from simulations S1 and S2 are robust, I conducted four additional simulations that extend $\mathrm{S} 1$ and $\mathrm{S} 2$ in various ways. These scenarios begin with the same response error distribution as scenarios $\mathrm{S} 1$ and $\mathrm{S} 2$. Scenario $\mathrm{S} 3$ is a variation of S1 where the continuous latent positions vary at uniform-random throughout the full latent range that corresponds to position $A, \operatorname{L} \sim \operatorname{Unif}(0,0.5)$. Scenario $\mathrm{S} 4$ extends $\mathrm{S} 1$ to three-category variables. In $\mathrm{S} 4$, true positions are constant at $\mathrm{L}=0.6$, and the discretization function yields 3-category items with cutpoints $q_{1}=0.333$ and $q_{2}=0.667$. Scenario S5 extends S2 by examining binarization artifacts that may come from off-center cutpoints: in S4, true positions are constant at $L=0.5$, but the discretization function has an off-center cutpoint $q_{1}=0.667$. Finally, scenario S6 further extends S5 by allowing the cutpoint to vary. In S6, true position is constant at $L=0.5$, but different variables in the simulated dataset are produced with different randomly determined cutpoints, $q_{1} \sim$ Unif $(0.5,1)$. All four of these scenarios again produced the same results as $\mathrm{S} 1$ and S2: a strong overall correlation corr $(\mathrm{P}(\mathrm{X}), \mathrm{P}(\mathrm{x} \mid \mathrm{X}))$ that vanishes when simulation results are disaggregated into minority and majority positions, instead yielding two negative correlations DRAFT ONLY - PLEASE DO NOT CITE WITHOUT PERMISSION 
$\operatorname{corr}(\mathrm{P}(\mathrm{A}), \mathrm{P}(\mathrm{a} \mid \mathrm{A}))<0$ and $\operatorname{corr}(\mathrm{P}(\mathrm{Z}), \mathrm{P}(\mathrm{z} \mid \mathrm{Z}))<0$. None of the simulations I examined could thus account for the observed correlation I report in this manuscript.

\section{Appendix H. "Don't Know" Responses and Missing Data}

While "Don't Know" responses (hereafter, "DK") are usually coded as missing data, it may be sensible to instead treat them as indicators of the neutral class $\varnothing$ in model $2 \mathrm{a}$, equivalently to the non-volunteered neutral/status quo responses. However, DKs are rare, and taking this approach often means adding a neutral class to a model that would not otherwise have one, which is a substantial cost to model complexity. To decide how to code DKs, I analyzed all the survey items under both coding approaches. I found that the approaches yielded substantively identical estimates: $\operatorname{cor}\left(P_{1}(X), P_{2}(X)\right) \approx 1.00$, and $\operatorname{cor}\left(P_{1}(x \mid X), P_{2}(x \mid X)\right) \approx 0.99$. The choice of how to code DKs is thus substantively unimportant. The results I present in this paper come from coding DKs as missing data, as this decision results in the more accurate classification of some survey items as two-category rather than three-category.

When dealing with missing data more broadly, for each survey item, I dropped any respondent that did not answer it on one or more waves. Since position-holding models are estimated separately for each item, I dropped respondents only when estimating position-holding models for items where they had missing responses. They did not need to be dropped from analyses of other items.

\section{Appendix I. Support for "Current" Policies}

Many of the 3-category GSS items implicitly ask about support for the "current" government. All 28 items whose names begin with nat- ask whether "we're spending too much money" on 
issues like welfare and environmental protection. Two other items probe support for current immigration levels (letin1) and the current size and scope of government (helpnot.) Three additional items probe the respondent's confidence in the executive branch, Congress, and the Supreme Court. Since all of the three branches of government changed their composition between 2008 and 2010, the meaning of these 33 items may have shifted as well. To ascertain that this is not artificially inflating my unreliability estimates, I re-estimated the 3-position models A, B, and C from Table 2 with these 33 items dropped from the analysis. In the resulting models A', B', and C', the estimated coefficient for popularity's effect on reliability were $0.391^{* * *}(0.075), 0.322^{* * *}(0.066)$, and $0.309^{* * *}(0.066)$. These estimated effects are somewhat smaller in magnitude than those in Table 2, but remain strong and highly statistically significant. They thus continue to support my primary conclusions. 